This item was submitted to Loughborough's Research Repository by the author.

Items in Figshare are protected by copyright, with all rights reserved, unless otherwise indicated.

\title{
Preparation of microemulsions and nanoemulsions by membrane emulsification
}

PLEASE CITE THE PUBLISHED VERSION

https://doi.org/10.1016/j.colsurfa.2019.123709

PUBLISHER

Elsevier

VERSION

AM (Accepted Manuscript)

\section{PUBLISHER STATEMENT}

This paper was accepted for publication in the journal Colloids and Surfaces A: Physicochemical and Engineering Aspects and the definitive published version is available at https://doi.org/10.1016/j.colsurfa.2019.123709

\section{LICENCE}

CC BY-NC-ND 4.0

\section{REPOSITORY RECORD}

Vladisavljevic, Goran T.. 2019. "Preparation of Microemulsions and Nanoemulsions by Membrane Emulsification”. figshare. https://hdl.handle.net/2134/38374. 


\title{
Preparation of microemulsions and nanoemulsions by membrane emulsification
}

\author{
Goran T. Vladisavljević
}

Chemical Engineering Department, Loughborough University, Loughborough, Leicestershire LE11 3TU, United Kingdom, Email: G.Vladisavljevic@lboro.ac.uk

\begin{abstract}
This paper is an overview of the applications of microporous membranes for preparation of micro/nano- emulsions. Membrane emulsification offers compact devices for preparation of nanoemulsions with low energy consumption, tuneable droplet size, monomodal distribution, and high encapsulation efficiency of entrapped functional components without shear or thermal degradation. The properties and wettability modification of Shirasu Porous Glass (SPG) membrane, track-etched polymeric sheets, syringe filters, anodic alumina membrane, and nickel-based superalloy membranes were discussed, as well as the design and operation of membrane devices. Particular emphasis was placed on the effect of formulation, operating parameters, and membrane properties on the resulting droplet size in direct and premix membrane emulsification with the examples of nano-sized emulsions produced using different membranes. The application of microemulsions prepared using synthetic membranes for production of solid self-microemulsifying drug delivery systems for enhanced solubility and oral bioavailability of BSC Class II and III drugs was also reviewed, as well as production of solid nanoparticles such as nanogels, solid lipid nanoparticles, synthetic biodegradable polymer nanoparticles, silica and metal oxide nanoparticles from nanoemulsion templates prepared by membrane emulsification.
\end{abstract}

Keywords: Membrane; Microemulsion Formation; Nanoemulsion Formation; Surfactants; Nanoparticles; Drug Delivery Systems. 


\section{Introduction}

Membrane emulsification has emerged as a new energy-efficient technique for preparation of microemulsions and nanoemulsions with tuneable droplet size. Direct membrane emulsification (direct ME, Figure 1a) involves formation of droplets from two separate immiscible liquids by injecting the dispersed phase under pressure through a microporous membrane into the continuous phase [1, 2]. Low shear rates between $10^{5} \mathrm{~s}^{-1}$ and $2 \times 10^{5} \mathrm{~s}^{-1}$ can be applied at the interface between the membrane surface and the continuous phase to overcome the capillary force and facilitate detachment of droplets from the pore mouths. However, droplets can be formed in dripping regime without external shear by exploiting Laplace pressure gradient established due to curvature imbalance along the interface occurring when the forming droplets squeeze each other on the membrane surface due to steric hindrance [3] or when they are detached from pores of irregular shape [4, 5].

Premix ME (Figure 1b) or membrane homogenisation involves reduction of droplet size by passing a pre-existing emulsion through the membrane [6] or a packed bed of microparticles [7, 8]. Droplets are disrupted by internal shear in the pores caused by transmembrane flow and the external shear is not necessary. A recent study has shown that premix ME can be achieved by pumping through the membrane a co-flow stream of the dispersed and continuous phase without a pre-emulsification step [9].

Wetting the pore walls by the dispersed phase can lead to complete phase separation [10] or phase inversion in the feed emulsion [11]. Therefore, hydrophobic membranes are used to inject an aqueous solution or oil-in-water emulsion into the external oil phase [12, 13], and hydrophilic membranes are used to inject an oil phase or water-in-oil emulsion into the external aqueous phase (Figure 1). 
(a) Direct membrane emulsification

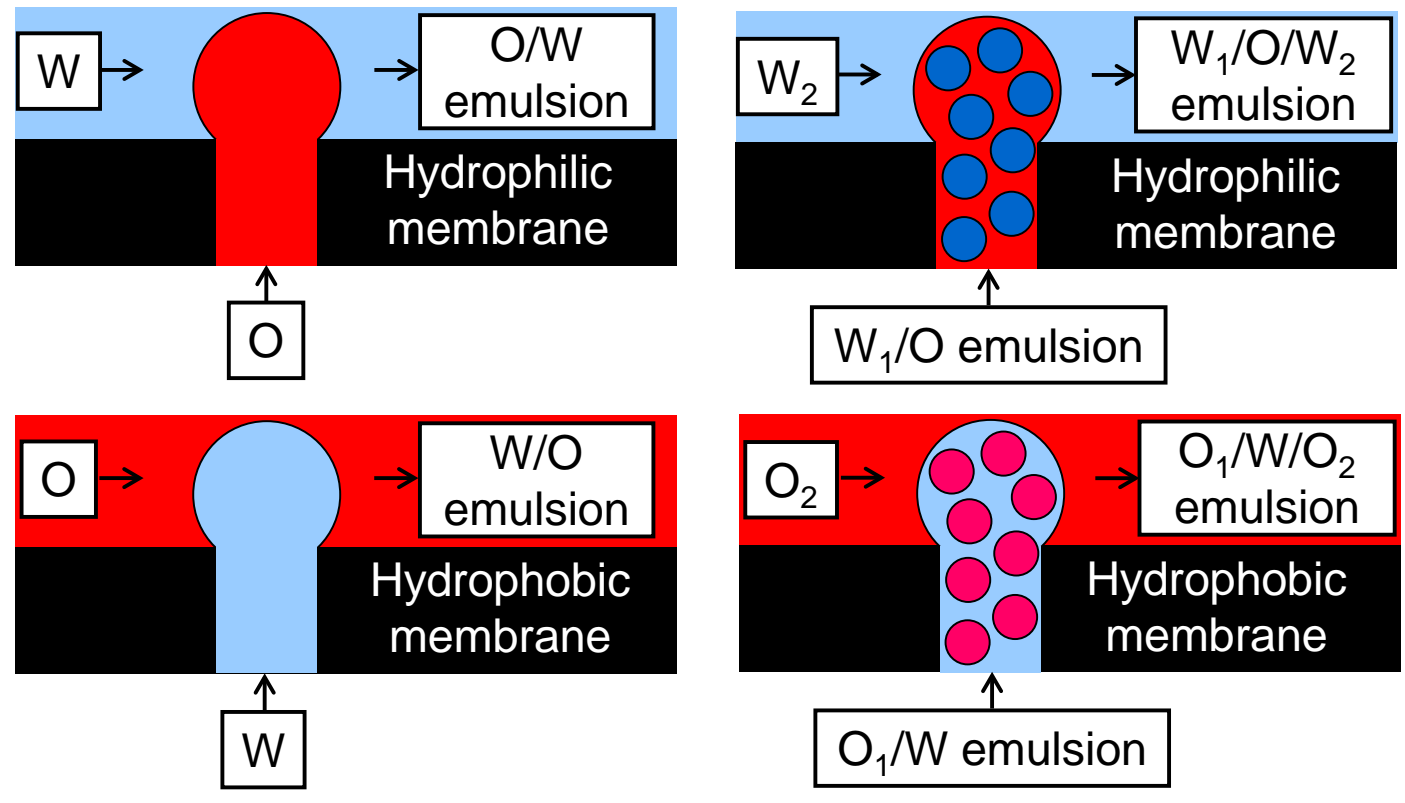

(b) Premix membrane emulsification
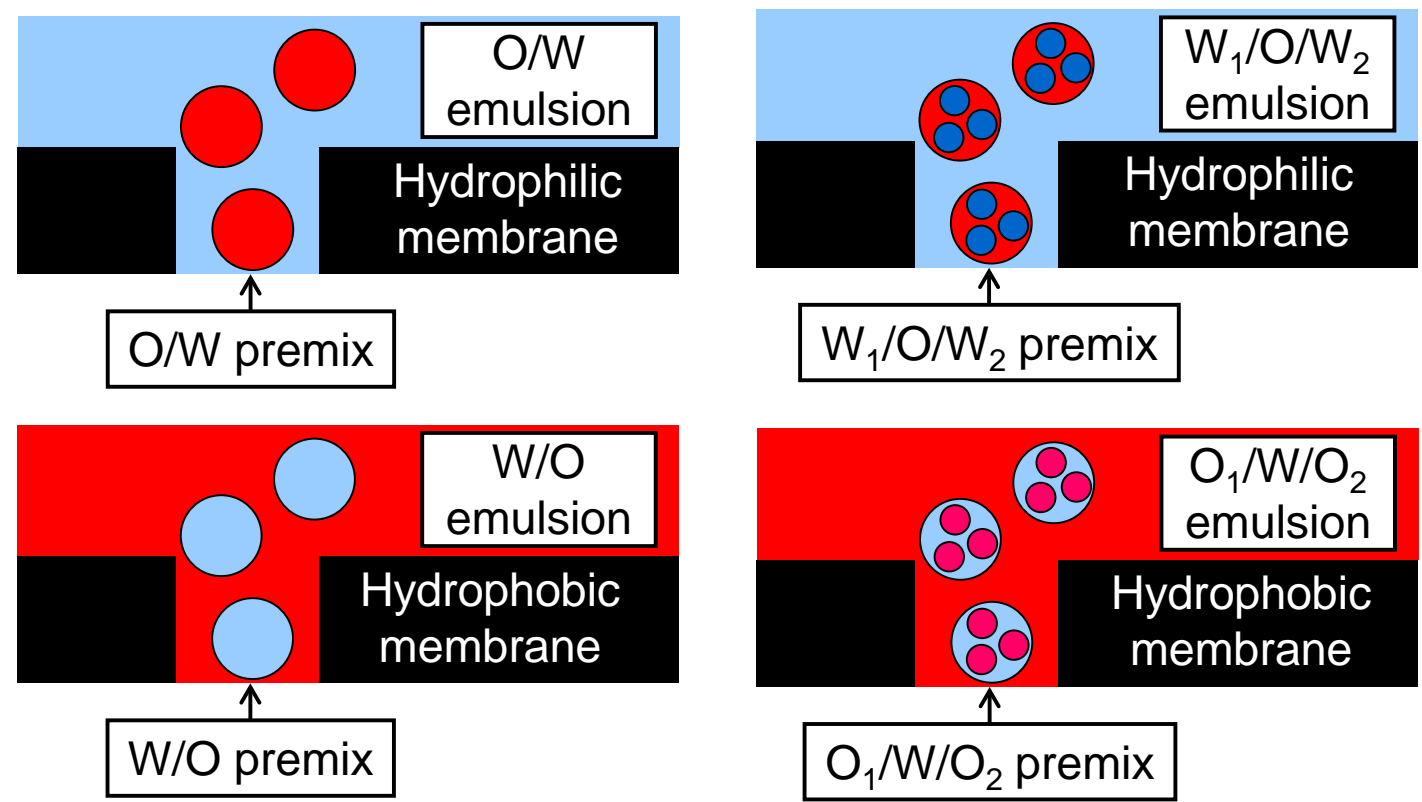

Figure 1. Emulsion types that can be produced using membrane emulsification and the required wettability of the membrane.

ME is performed under mild shear conditions, leading to isothermal processing and high entrapment efficiency of encapsulants [14]. Heat-sensitive ingredients can be damaged in conventional homogenisers due to high energy inputs [15]. The shear rate in colloid mills is 
$(1-2) \times 10^{5} \mathrm{~s}^{-1}$, up to $10^{7} \mathrm{~s}^{-1}$ in high-pressure homogenisers, and below $10^{4} \mathrm{~s}^{-1}$ in premix ME . Another potential advantage of ME is in higher stability of nanoemulsions because Ostwald ripening is supressed with narrowing particle size distribution. A parenteral nanoemulsion prepared by premix $\mathrm{ME}$ and stored under stressed conditions at $40{ }^{\circ} \mathrm{C}$ was found to be more stable than the same emulsion prepared using Microfluidizer ${ }^{\circledR}$ [16].

This review aims to summarise the applications of microporous membranes for preparation of micro/nanoemulsions. The review covers only processes in which the dispersed phase forms droplets in the continuous phase and does not include membrane nanoprecipitation, in which the dispersed phase solvent is miscible with the continuous phase liquid leading to solvent displacement at the interface and precipitation of the material(s) initially dissolved in the dispersed phase [17].

\section{Nano/Micro-porous Membranes for Emulsification}

Membranes for micro/nano-emulsification should have narrow pore size distribution, low resistance to flow, excellent mechanical and chemical durability, high thermal resistance, wettability that can easily be modified, and should be biocompatible, sterilisable and cheap. SPG membrane allows easy surface modification but offers high resistance to flow due to high thickness. The minimum pore size of SPG membrane $(100 \mathrm{~nm})$ is larger than that of tracketched membranes $(15 \mathrm{~nm})$ and anodic alumina membrane (5 $\mathrm{nm})$, but smaller than that of stainless-steel membrane with laser drilled pores $(2 \mu \mathrm{m})$. Polymeric syringe filters have the highest porosity (60-76\%), followed by SPG membrane (50-60\%), and track-etched membrane (5-30\%). Nickel membranes with electroformed pores have the lowest porosity of $0.05-25 \%$. Polymeric syringe filters are the cheapest membranes and often used as disposable filters [18]. 

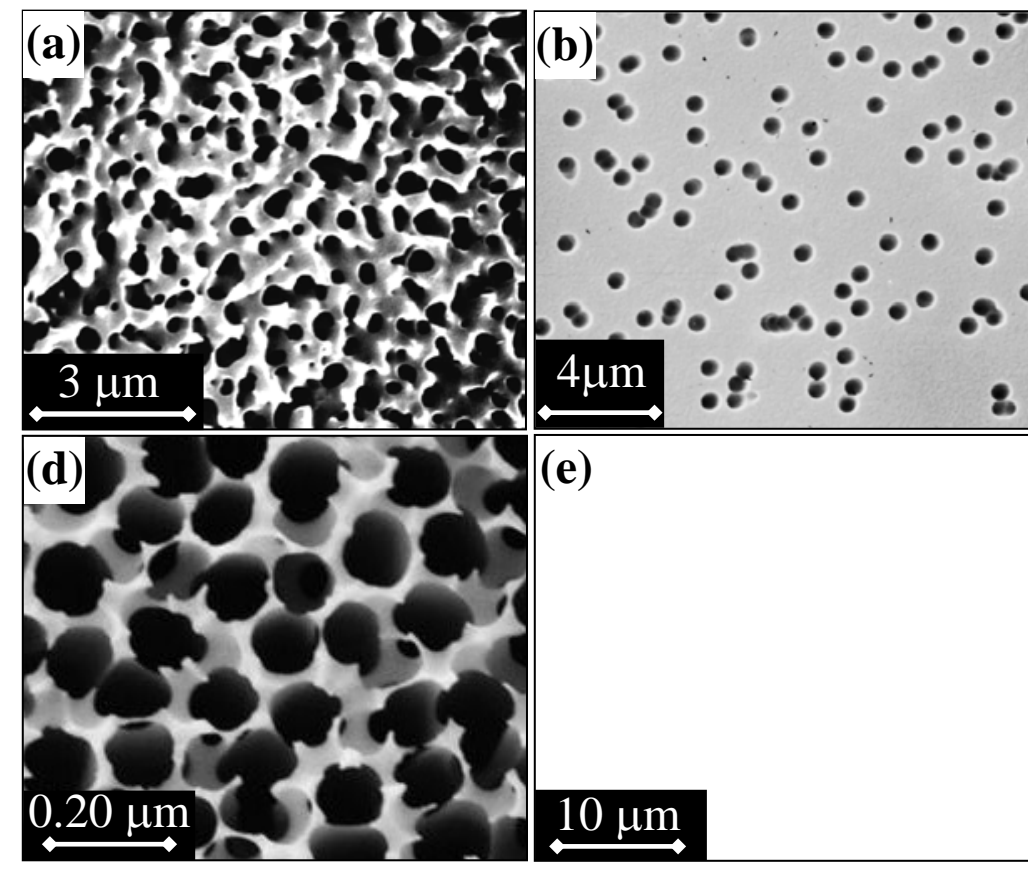

(e)
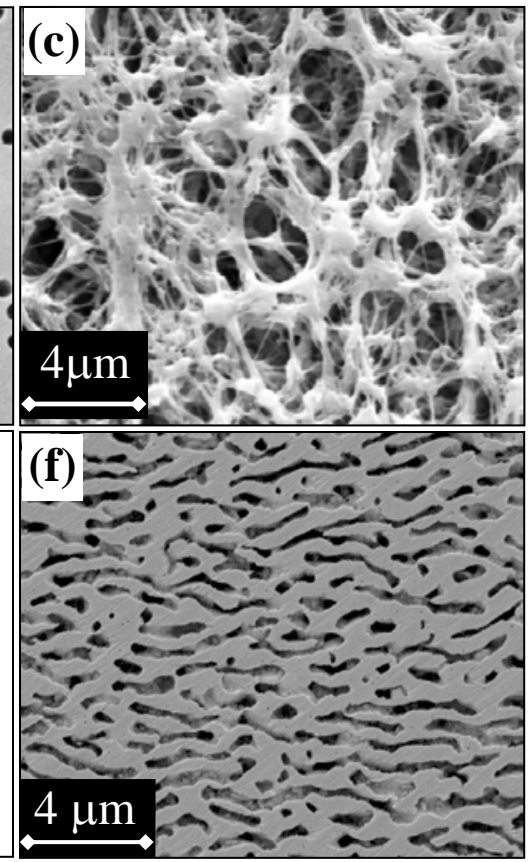

Figure 2. SEM images of nanoporous membranes used for production of nanoemulsions: (a) SPG membrane with a mean pore size of $260 \mathrm{~nm}$ [19]; (b) Track-etched polycarbonate (PC) membrane with a pore size of $670 \mathrm{~nm}$ manufactured by irradiating nonporous PC film with $\mathrm{Cu}^{3+}$ [20]; (c) Hydrophilised polypropylene membrane filter with a pore size of $200 \mathrm{~nm}$ [21]; (d) Whatman ${ }^{\circledR}$ Anopore membrane with a pore size of $100 \mathrm{~nm}$ [22]; (e) Ni-based superalloy load-free (LF)-coarsened $\gamma^{\prime}$ membrane [23]; (f) Ni-based superalloy thermo-mechanically (TM)-coarsened $\gamma^{\prime}$ membrane [23].

SPG membranes. These membranes are manufactured from Shirasu (volcanic ash deposit), $\mathrm{CaCO}_{3}$, and boric acid by spinodal phase separation at high temperature and subsequent acid leaching of $\mathrm{CaCO}_{3} / \mathrm{B}_{2} \mathrm{O}_{3}$-rich phase [24]. The pore size can be tuned by adjusting the temperature and duration of phase separation [25]. SPG membrane has a thickness of 700-900 $\mu \mathrm{m}$ and a pore density of $10^{5}-10^{9} \mathrm{~cm}^{-2}$ [26]. The pores are highly interconnected (Fig. 2a) with a tortuosity of 1.3. Durability of SPG at high pH values is limited but can be enhanced by adding $\mathrm{ZrO}_{2}$ during glass formation [25]. SPG membrane is negatively charged and inherently hydrophilic [27] but can be turned to hydrophobic by treatment with organosilane coupling agents or coating with silicon resins [28, 19]. 
Track-etched polymeric membranes. Membranes with track-etched pores can be fabricated by exposing a nonporous polymer sheet to alpha particles or accelerated heavy ion beams, followed by wet etching of latent tracks to form holes [29]. Track-etched membranes are usually manufactured from polycarbonate (PC), polyimide (PI), and polyesters (PEs), e.g. polyethylene terephthalate (PET). The pore density $\left(10^{0}-10^{8} \mathrm{~cm}^{-2}\right)$ depends on the irradiation time and the pore size $(0.015-12 \mu \mathrm{m})$ depends on the etching time. Due to their smaller thickness (less than $30 \mu \mathrm{m}$ ) and straight pores (Fig. 2b), track-etched membranes are less prone to fouling than SPG membranes. However, pores are randomly spaced which can lead to very small distance between some adjacent pores and potential steric hindrance between droplets. PC membranes are hydrophobic but can be rendered hydrophilic by treatment with oxygen plasma [30].

Polymeric syringe filters can be prepared by phase inversion process [31] in polymers such as polytetrafluoroethylene (PTFE), polyethersulfone (PES), polyvinylidene fluoride (PVDF), nylon, cellulose acetate (CA), mixed cellulose ester (MCE), and polyesters (PEs) [32]. Syringe filters have highly porous sponge-like structure (Fig. 2c) with a broad pore size distribution and a thickness of 20-200 $\mu \mathrm{m}$ [30].

Microsieve membranes. Microsieve membranes have uniform pores arranged in regular arrays which can be made by electroplating [33, 34], ion etching [35, 36], laser ablation [14, 37], and anodic oxidation [38-40]. Anodic alumina membrane (AAM) has a pore size of 5-400 nm and a distance between the pores of 20-600 nm [41]. This membrane is hydrophilic due to $\mathrm{Al}_{2} \mathrm{O}_{3}$ film on the surface but can be put in contact with $\left[\left(\mathrm{CH}_{3}\right)_{3} \mathrm{Si}\right]_{2} \mathrm{NH}$ vapor to become hydrophobic [42]. Commercial Anopore ${ }^{\mathrm{TM}}$ AAMs have densely-packed honeycomb pore structure (Fig. 2d) with a pore size of $20-200 \mathrm{~nm}$.

Ni-based Superalloy Membranes. These membranes are manufactured by precipitating $\mathrm{Ni}_{3} \mathrm{Al}$ (the $\gamma^{\prime}$-phase) out of a Ni-rich solid phase (the $\gamma$-phase) through thermo-mechanical or loadfree thermal treatment and subsequent electrochemical leaching of either $\gamma^{\prime}$ or $\gamma$ phase [23]. The resulting membranes have irregular and interconnected pores, in the case of load-free thermal treatment (Fig. 2e) or channel-like pores, in the case of thermo-mechanical treatment (Fig. 2f). The Ni-based superalloy membranes have superior mechanical properties, high 
chemical and thermal resistance. The membrane thickness is about $300 \mathrm{~nm}$ and the pore size ranges from several hundred nanometres to several microns.

\section{Microemulsions vs. Nanoemulsions}

Microemulsions are thermodynamically stable systems consisting of droplets that do not have to be spherical due to extremely low interfacial tension. They are formed spontaneously through thermodynamic self-assembly [43, 44]. Nanoemulsions are thermodynamically unstable system consisting of spherical droplets formed usually by applying high external shear although low energy methods (phase inversion temperature and phase inversion composition) can also be used. The average droplet diameter in both systems is below $200 \mathrm{~nm}$ [43] which make them optically transparent. The optical transparency contributed to widespread applications of both systems in production of clear food products and beverages. However, this review will cover all emulsions with submicron droplet sizes produced using porous membranes. Microemulsions are formed by mixing oil, water, surfactant and possibly a co-surfactant using very low energy input needed to exceed a moderate energy barrier known as the activation energy, $\Delta G^{*}$. In direct $\mathrm{ME}$, low energy is supplied in the form of transmembrane pressure which is typically below $100 \mathrm{kPa}$ or $1 \mathrm{~kJ} \mathrm{~m}^{-3}$ and providing gentle shearing on the membrane surface [45]. It should be noted that a microemulsion can only be formed within a specific range of concentrations of water, oil, and surfactants. A ternary phase diagram for an $\mathrm{O} / \mathrm{W}$ emulsion composed of dichloromethane (DCM), water, and an equivolume mixture of Tween 20 and Tween 80 is shown in Figure 3.

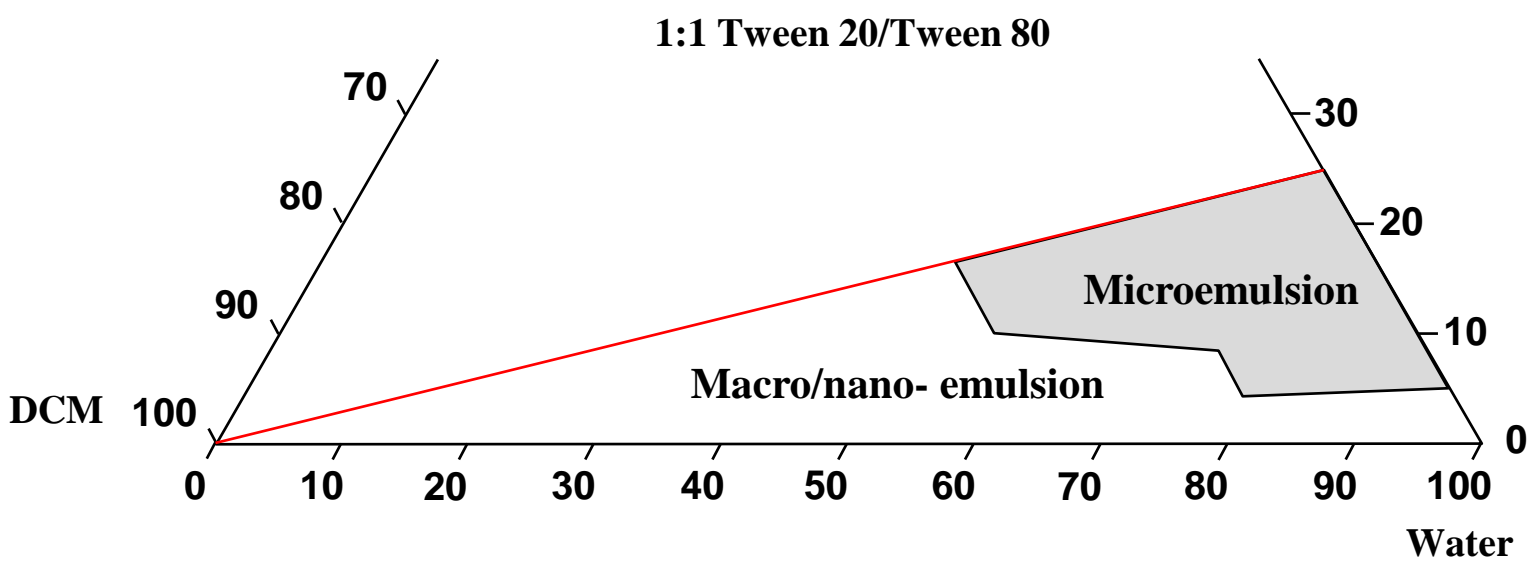


Figure 3. The ternary phase diagram for the dispersed system composed of dichloromethane (DCM), water and 1:1 (vol/vol) blend of Tween 80 and Tween 20 [45]. Within the grey microemulsion region, the drop size in direct $\mathrm{ME}$ is much smaller than the membrane pore size and independent on the pore size. Within the macro/nano -emulsion region, the drop size in direct ME is larger than the pore size.

Microemulsions can only be formed within a grey-shaded area, i.e. for high surfactant concentrations (5-25\%) and low DCM concentrations. Depending on the amount of energy used to disperse DCM in the aqueous solution, either $\mathrm{O} / \mathrm{W}$ macroemulsions or nanoemulsions will be formed outside the zone of microemulsion stability.

\section{Preparation of Microemulsions using Membranes}

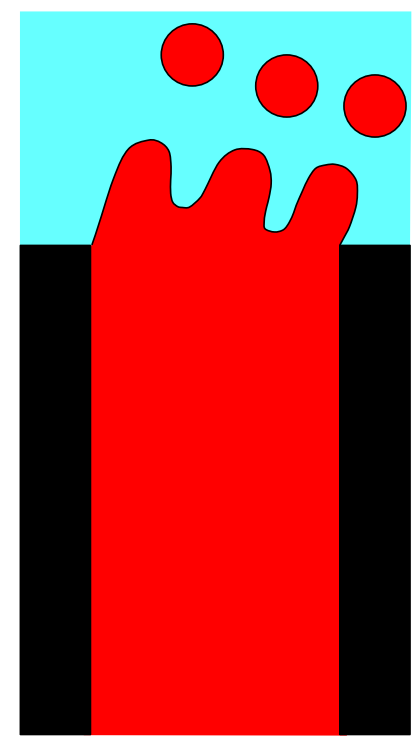

(a)

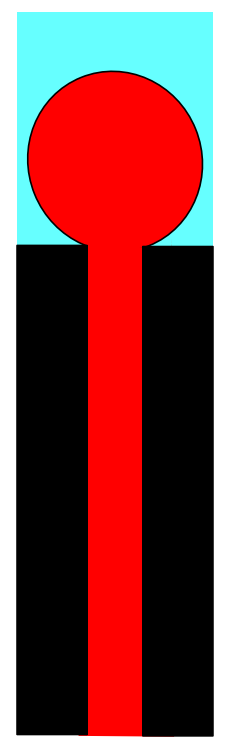

(b)

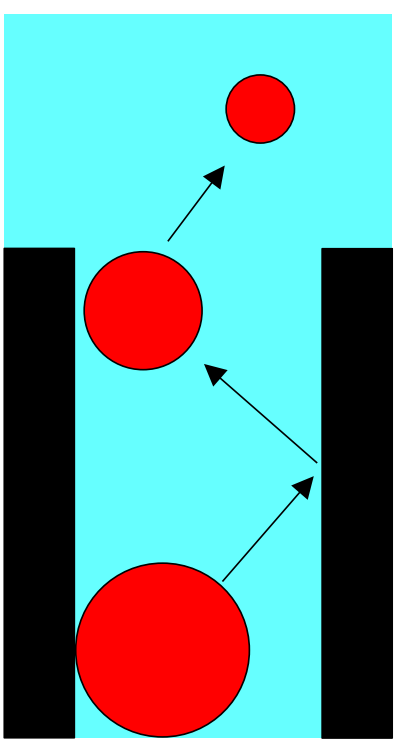

(c)

Figure 4. Oil nanodroplets prepared using different membrane emulsification techniques: (a) Microemulsion droplets prepared by direct ME; (b) Nanoemulsion droplets prepared by direct ME; (c) Nanoemulsion droplets prepared by premix ME. 
Figure 4a shows schematically preparation of microemulsions using a microporous membrane. Membrane pores provide numerous micromixing points, which help to achieve uniform introduction of small pockets of the dispersed phase directly into the continuous phase. A droplet detaching from the pore outlet disintegrates into tiny droplets either at the membrane surface or within a bulk of the continuous phase. The final droplet size is typically 2-50 times smaller than the pore size (Fig. 4a, Table 1) and depends on formulation parameters and local distribution of concentration and velocity during microemulsion formation, which can be precisely controlled in membrane emulsification systems. There are many evidences showing that microemulsions prepared by ME can be prepared with tuneable droplet sizes. Also, they tend to show narrower size distributions than those prepared by stirring without membrane. For example, when a fenofibrate-loaded microemulsion was prepared via a 1.1- $\mu \mathrm{m}$ SPG membrane, a polydispersity index (PDI) of 0.07 was achieved, while PDI was 0.29 when the same emulsion was prepared by simple stirring at the same conditions [47]. However. more investigations are needed to support this hypothesis.

\subsection{Critical Surfactant Concentration for Microemulsion Formation}

The minimum amount of surfactant needed to create a microemulsion can be determined by preparing emulsions with increasing concentration of surfactant using direct ME and detecting the surfactant concentration at which the droplet size will suddenly decrease below the pore size of the membrane. Fig. 5 shows droplet sizes of squalene emulsions prepared with different amounts of docusate sodium (AOT) added to squalene as a surfactant [49]. Macroemulsions were produced for the AOT concentrations in the dispersed phase below $0.01 \mathrm{M}$. In this region, the droplet size (2-5 $\mu \mathrm{m})$ was at least 5 times larger than the pore size of $0.4 \mu \mathrm{m}$ and could be accurately predicted by a force balance model, as shown by the dashed line in Figure 5. Smaller droplets were formed at higher AOT concentrations due to the lower interfacial tension leading to the lower capillary force at the pore openings. Microemulsions were formed at the AOT concentrations above 0.01 M. In this region, the mean droplet size was 2-5 times smaller than the pore size and could not be predicted by the force balance model, because this model is valid only for the interfacial-tension driven drop generation process. Therefore, the critical surfactant concentration to produce microemulsions was $0.01 \mathrm{M}$. 


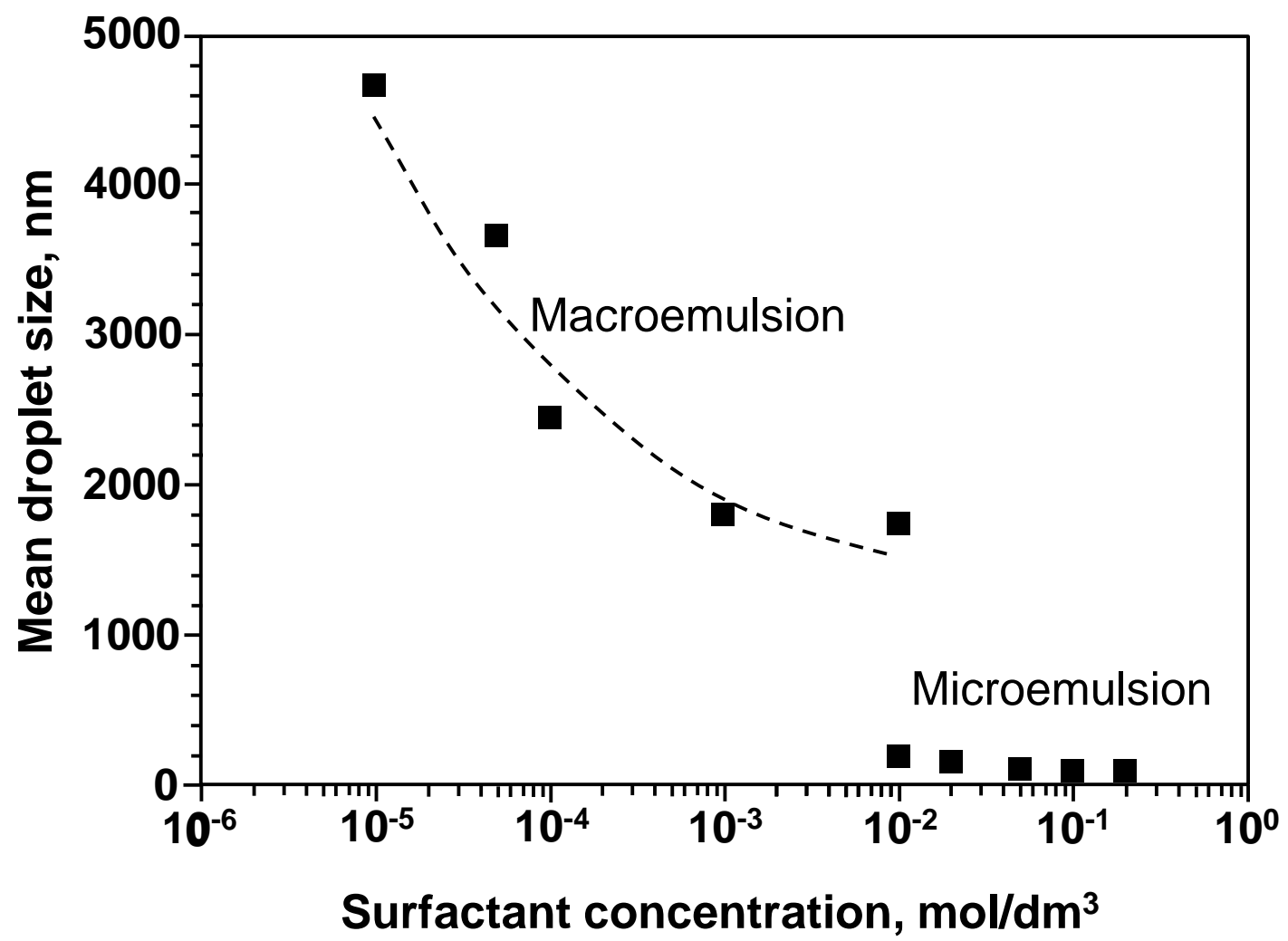

Figure 5. The effect of concentration of AOT (docusate sodium) in the dispersed phase on the mean size of squalene droplets formed by direct ME in a stirred cell using ceramic membrane with a pore size of $0.4 \mu \mathrm{m}$ [49]. In the macroemulsion region, the average drop size was several times larger than the membrane pore size, while in the microemulsion region, the average drop size was 2-5 times smaller than the membrane pore size. The dispersed phase was AOT solution in squalene and the continuous phase was $100 \mathrm{ppm}$ PAH dissolved in $0.015 \mathrm{M} \mathrm{NaCl}$ solution.

\subsection{Surfactants Suitable for Microemulsion Formation}

To screen surfactants for microemulsion formation, multiple emulsions were prepared using 7 different hydrophilic surfactants (Table 2B [52]). A rotor/stator homogeniser was used to obtain a $\mathrm{W}_{1} / \mathrm{O}$ emulsion and a $100-\mathrm{nm}$ SPG membrane was used to produce a $\mathrm{W}_{1} / \mathrm{O} / \mathrm{W}_{2}$ emulsion. If the outer aqueous phase was pure water or $1 \mathrm{wt} \%$ solution of Gelucire 44/14, L-7D or Labrasol, the droplet size was $\sim 320 \mathrm{~nm}$. The droplet to pore size ratio of 3.2 suggests that the interfacial tension was too high to form a microemulsion. If the outer aqueous phase was $1 \mathrm{wt} \% \mathrm{HS}-11$, a mixture of 1 wt\% HS-11 and 1 wt\% PVA, or a mixture of 1 wt $\%$ Gelucire 44/14 and 1 wt\% 
PVA, the droplet size was 105-143 nm pointing out to the formation of a microemulsion. If the other aqueous phase was $1 \mathrm{wt} \% \mathrm{~S}-24 \mathrm{D}, 1 \mathrm{wt} \% \mathrm{~S}-28 \mathrm{D}$ or $1 \mathrm{wt} \%$ HS-9, the droplet size was 790-1750 nm, indicating that these surfactants were not suitable for the preparation of neither nanoemulsions nor microemulsions using SPG membrane.

\section{Preparation of Nanoemulsions using Membranes}

Nanoemulsion droplets prepared by direct ME are approximately 2-9 times larger than the pores (Fig. 4b) (Table 2). Due to much smaller pore sizes (typically 50-200 nm), higher transmembrane pressures are needed to make nanoemulsions than microemulsions (up to 50 bar for SPG membrane and up to 350 bar for polymeric syringe filters). Nanoemulsion droplets prepared by premix ME are often 2-3 times smaller than the pore size of the membrane after multiple extrusion cycles (Fig. 4c and Table 3). However, depending on the formulations and operating conditions, the droplet to pore size ratio in premix ME can be as high as 3 [18].

\section{Membrane Emulsification Equipment for Preparation of Micro/Nano - Emulsions}

\subsection{Equipment for Direct ME}

Micro/nano-emulsions can be prepared by direct ME using cross-flow modules with long tubular membranes (usually 100-500 mm in length), SPG micro kits with short tubular membranes (usually 7-20 mm in length), and stirred cells with flat membrane discs.

Cross-flow devices. In this setup, the continuous phase is continuously recirculated between a vessel and a membrane module (Fig. 6a). The dispersed phase is injected from the outer side of the membrane tube into the continuous phase stream inside the membrane tube until the desired concentration of the dispersed phase is reached in the emulsion. A droplet throughput can be increased by adding additional membrane tubes or by increasing the length of the tube. To decrease recirculation rate through the device while maintaining high shear at the membrane surface, membrane tube can be equipped with static turbulence promoters [55] or back-andforth pulsations of the continuous phase stream can be superimposed on cross flow [56, 57]. Due to long operation times, droplets formed by the membrane pores can be broken up into 
smaller droplets inside the pump, which leads to a reduction in the average droplet size [58, 59]. The phenomenon can be avoided using low-shear pumps, such as a "Mohno" pump [60].

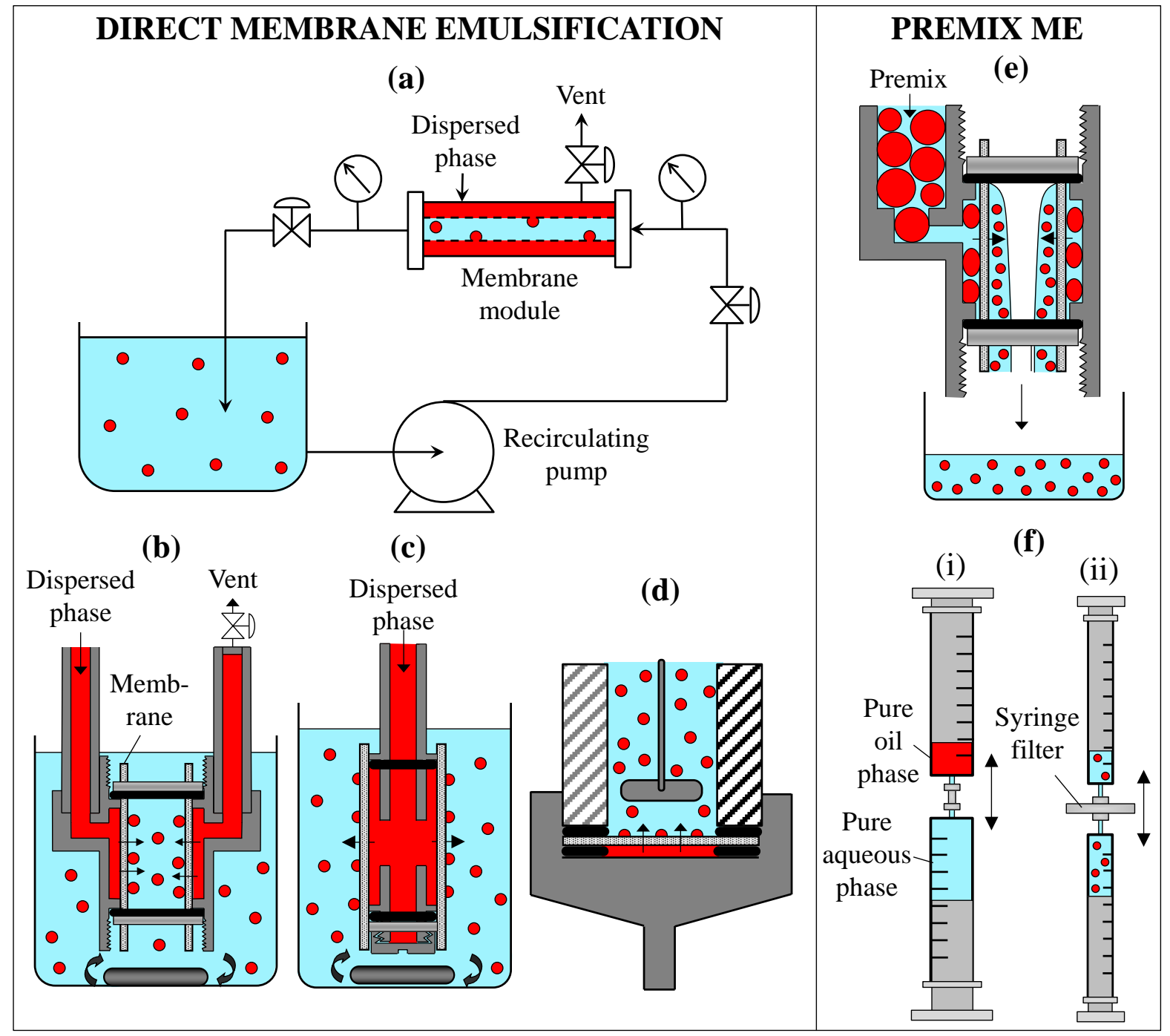

Figure 6. Typical membrane devices for preparation of micro/nanoemulsions: (a) Cross-flow system; (b) External pressure type SPG micro kit for direct ME; (c) Internal pressure type SPG micro kit for direct ME; (d) Stirred cell for direct ME [53]; (e) External pressure type SPG micro kit for premix ME; (f) Extrusion through syringe filter: (i) formation of premix by pushing pure oil and pure aqueous phase back and forth multiple times between two syringes and (ii) homogenisation of premix by pushing it back and forth multiple times through a syringe filter placed between two syringes [54]. The dispersed phase location is shown in red, whilst the continuous phase position is shown in turquoise. 
SPG Micro Kits. The amount of continuous phase in SPG micro kits (Figs. 6b-c) could be very small, just enough to submerge a 20-mm long SPG tube. The dispersed phase consumption is very low due to small volume of the continuous phase, which is useful for testing emulsions containing expensive drug candidates [61]. In the external pressure kit (Fig. 6b), the dispersed phase is injected from outside the membrane tube to the inside and the droplets are formed at the inner membrane surface. The continuous phase flows downwards through the membrane tube sucked by a stirring bar rotating at the bottom of the beaker. To emulsify melted lipids, the beaker must be placed on a hotplate and a vessel for the dispersed phase must be heated [51].

In the internal pressure kit (Fig. 6c), the dispersed phase is injected from inside the membrane tube and droplets are formed at the external surface of the membrane [46]. A disadvantage of this kit is the lower maximum pressure that can be applied (300 kPa), as compared to $1000 \mathrm{kPa}$ that can be used in the external pressure kit [51]. SPG filter kit is a special type of internal pressure kit in which the dispersed phase is injected using a built-in stainless steel syringe. The membrane tube is immersed in a vial loaded with less than $10 \mathrm{~mL}$ of the continuous phase [52].

Stirred cells with flat membrane. The schematic view of a batch stirred cell for production of nanoemulsions was shown in Fig. 6d [53]. The cell consists of a cylindrical tank filled with the dispersed phase, which is fitted to the membrane holder where a flat anodic alumina membrane was placed. The dispersed phase was pushed through the membrane with a syringe pump and the shear was provided via an overhead stirrer rotated above the membrane surface. This cell can be modified to allow a semi-continuous operation with a continuous introduction of fresh continuous phase and a continuous withdrawal of the emulsion [62]. A disadvantage of stirred systems is a non-uniform shear on the membrane surface ranging from zero at the axis of rotation to the maximum value corresponding to one-third of the distance between the axis of rotation and the tank wall [63]. More uniform shear distribution can be achieved using a ringshaped membrane in which the pores are only located in a narrow annulus encompassing the maximum shear region [62].

Scale-up for industrial scale processes. Industrial scale ME devices should allow a continuous operation and reasonable throughputs. The main restriction for continuous operation is a low dispersed phase concentration that can be achieved in a single pass of the continuous phase over 
the membrane in conventional cross flow modules. However, by using pulsed (oscillatory) flow of the continuous phase in cross flow modules, it was possible to provide dispersed phase concentrations of up to $45 \% \mathrm{v} / \mathrm{v}$ in a single pass over the membrane [57]. Cross flow modules with pulsed flow of the continuous phase can be interfaced with a reactor downstream of the droplet generation unit to integrate droplet generation and reaction into a single continuous flow process. Another method of achieving high dispersed phase concentrations in a single pass is to apply oscillating membrane emulsification (OME) systems based on using a nonstationary cylindrical membrane rotating fully in the same direction [64] or periodically clockwise and counterclockwise [65]. It should be noted that ME systems with pulsed flow and oscillating membrane have not yet been used for generation of nanoemulsions.

\subsection{Equipment for Premix ME}

External pressure SPG Micro Kit. In this kit, a 20-mm long SPG tube is installed in a stainless-steel module and suspended above a collection beaker (Fig. 6e). The premix is injected through the membrane from the external side and the product emulsion is formed inside the tube and flows into the beaker underneath the membrane. To increase the throughput, an adapted cross-flow module with a 125-mm long SPG tube can be used instead of the short tube [66]. The extrusion process can be repeated multiple times ([67-68].

Syringe filters. Syringe filters have been widely used for homogenisation of liposomes [70] but can be also used for preparation of nanoemulsions (Fig. 6f). Commercial membrane extruders consist of two syringes mounted on each side of a stainless-steel holder, which holds a syringe filter [18]. The extrusion process consists of two steps: (i) Mixing together an oil and aqueous phase by transferring the liquids several times between the two syringes, and (ii) Homogenising the mixture formed in the previous step by pushing it back and forth through a syringe filter installed between the two syringes [32]. The advantages of commercial membrane extruders are in extremely small emulsion volumes that can be produced (as small as $0.2 \mathrm{~mL}$ ), short extrusion times, and possible automation of the extrusion process [54]. The sample volume can be increased up to 1 litre using commercial homogenisers in which a standard homogenising valve was replaced with a membrane extruder unit [32]. 


\section{Tuning Droplet Size in Direct ME}

Transmembrane Pressure. The applied pressure difference to form a microemulsion is less than 1 bar, due to very low capillary pressure and large pore size (typically above $1 \mu \mathrm{m}$ ). In most cases, higher transmembrane pressure led to larger droplets and higher polydispersity of droplet sizes [46, 48]. For example, an increase in droplet size from $410 \mathrm{~nm}$ to $550 \mathrm{~nm}$ was observed when the pressure across a $2.5-\mu \mathrm{m}$ SPG membrane increased by $25 \mathrm{kPa}$ [46].

The transmembrane pressure needed to produce a nanoemulsion is much higher than that for a microemulsion due to higher interfacial tension and smaller pore size. For example, to prepare soybean oil nanoemulsions using a $0.1-\mu \mathrm{m}$ SPG membrane, the driving pressure was $800 \mathrm{kPa}$ [51]. The optimum pressure in dripping regime is $5 \mathrm{kPa}$ above the capillary pressure (for a 0.3$\mu \mathrm{m}$ SPG membrane) and $20 \mathrm{kPa}$ above the critical pressure (for a 0.1- $\mu \mathrm{m}$ SPG membrane) [51]. Larger droplets are formed at higher pressures due to a finite necking time [71] but uniform droplets persist within the dripping regime [72]. The transition from dripping to continuous outflow occurs at the critical velocity in the pores which does not depend on the pore size [36] and increases with increasing the dispersed to continuous phase viscosity ratio [73].

Membrane pore size. Membrane pore size does not have a significant impact on the size of microemulsion droplets up to the pore size of several microns, but too large pore sizes should be avoided. Laouini et al. [48] prepared O/W microemulsions loaded with vitamin E using SPG membranes with a pore size of $0.4 \mu \mathrm{m}, 0.9 \mu \mathrm{m}$ and $10.2 \mu \mathrm{m}$. The droplet size was similar for the $0.4-\mu \mathrm{m}$ and $0.9-\mu \mathrm{m}$ membranes (150-160 nm), but when the 10.2- $\mu \mathrm{m}$ membrane was used, the droplet size distribution was very broad with the droplet size of several microns. In most cases, the pore size of SPG membrane was $2.5 \mu \mathrm{m}$ or less to prepare a microemulsion with $d_{50}$ $<200 \mathrm{~nm}$ (Table 1).

To prepare O/W nanoemulsions by direct ME, the maximum pore size of SPG membrane was 0.2-0.3 $\mu \mathrm{m}$ [51] and the droplet size was often two orders of magnitude larger than that of microemulsions prepared using the same pore size. For example. the size of dichloromethane (DCM) droplets stabilised by a mixture of $5 \%(\mathrm{w} / \mathrm{v})$ Tween surfactants and 1\% (w/v) PVA produced using a 2.5- $\mu \mathrm{m}$ SPG membrane was below $100 \mathrm{~nm}$ [45]. The size of DCM droplets 
formed outside the microemulsion region with the same membrane using smaller amount of surfactant (1-2\% w/v) and without PVA would be $\sim 8 \mu \mathrm{m}$.

Under optimum conditions, the droplet size of nanoemulsions linearly increases with the pore size: $d_{\text {droplet }}=K^{\prime} d_{\text {pore }}$, where $K^{\prime}$ is 2.8-3.5 for SPG membrane [5, 69, 74] and 1.8-3.5 for AAM at $d_{\text {pore }}>50 \mathrm{~nm}[53,38]$. For SPG membrane $K^{\prime}$ was 3.3 even at zero shear [5]. For anodic alumina membrane $K^{\prime}$ was 4.9 at low shear stress [53]. The minimum pore size of AAM is about $5 \mathrm{~nm}$ and the droplet size corresponding to that pore size is less than $100 \mathrm{~nm} . K^{\prime}$ for AAM was found to increase with decreasing the pore size [40].

Shear rate. Laouini et al. [48] observed smaller droplets with narrower size distribution when microemulsions were prepared at higher cross flow velocities. Similarly, the size of silymarinloaded droplets prepared with a 2.5- $\mu \mathrm{m}$ SPG membrane decreased from $650 \mathrm{~nm}$ to $160 \mathrm{~nm}$ when the stirring rate was changed from 300 to $700 \mathrm{~nm}$ [75]. In some cases, microemulsions with larger droplets were formed at higher stirring rate due to increased coalescence probability.

During formation of nanoemulsions, droplets grow at the pore openings until the droplet-sizedependant drag force exceeds the pore-size-dependant capillary force. In most cases, $d_{d r o p}$ asymptotically decreases when the shear rate increases and stabilizes at high shear, which was broadly confirmed in different studies. Preparing nanoemulsions using AAM with a pore size of 25-60 nm smaller droplets were obtained at higher cross flow velocities [40, 66]. Compared with dead-end condition, crossflow velocity of $0.01 \mathrm{~m} \mathrm{~s}^{-1}$ provided a droplet size reduction of 25-50\%. The effect of shear stress was negligible at high cross-flow velocities (between 0.04 and $0.10 \mathrm{~m} \mathrm{~s}^{-1}$ ).

Temperature. Smaller droplets with more uniform size distribution were obtained at lower temperatures [48]. Temperature has a significant impact on the viscosity of bulk phases, interfacial tension, and the hydrophilic-lipophilic balance (HLB) of the surfactant used to stabilise droplets. Temperatures below the phase inversion temperature (PIT) favour the stability of $\mathrm{O} / \mathrm{W}$ emulsions. 
Surfactant type/concentration. A sufficiently high concentration of surfactant(s) is critically important to form an O/W microemulsion, as shown in Fig. 4. The higher the surfactant concentration the higher the amount of oil that can be incorporated in a microemulsion. Oil molecules can be incorporated into surfactant micelles in the form of microemulsion droplets until the micelles become fully saturated with oil [43]. Any further addition of oil through the membrane will lead to the formation of a separate oil phase with much larger droplets [43]. On the other hand, too high surfactant to oil ratio can lead to bimodal particle size distribution due to presence of both swollen micelles (microemulsion droplets) and oil-free micelles [48]. Mixed surfactant systems consisting of a surfactant and co-surfactant were used in most studies, with the total surfactant concentration in the emulsion of 2.25-5 wt\% [76]. Co-surfactant molecules have the ability to penetrate between the surfactant chains and change their molecular packing and mobility, thereby affecting the interfacial tension and emulsion stability [43].

Surfactants used to stabilise nanoemulsions should have a low molecular weight to diffuse fast to the liquid interface $[53,77,78]$ but should not stick to the membrane surface to alter the contact angle or block the membrane pores [79, 80]. In addition to the adsorption kinetics of surfactants and their possible interactions with the membrane wall, the equilibrium interfacial tension plays a significant role with smaller nanodroplets being formed at lower equilibrium interfacial tensions [51].

Stabilisers and encapsulants. The addition of stabilisers such as polyvinyl alcohol (PVA) could be crucial to form a stable microemulsion. The droplet to pore size ratio $\left(K^{\prime}\right)$ can be used as a criterion to confirm whether a microemulsion was formed. For example, the size of multiple emulsion droplets produced with a 0.1- $\mu \mathrm{m}$ SPG membrane was $316 \mathrm{~nm}$ when the outer aqueous phase was $1 \mathrm{wt} \%$ Gelucire 44/14 solution [52]. Therefore, $K^{\prime}$ was 3.16, which is within the expected range for SPG membrane indicating formation of a nanoemulsion. On the other hand, the droplet size was $143 \mathrm{~nm}$ when $1 \mathrm{wt} \%$ PVA was added to the outer phase. In this case, $K^{\prime}$ was 1.43 indicating self-emulsifying formulation. The presence of stabiliser is also important for storage stability of emulsions. When $1 \mathrm{wt} \%$ PVA was added to the outer phase of multiple emulsions stabilised by $1 \mathrm{wt} \%$ HS-11, after one week, the size of outer droplets was one-half of the size of droplets stabilised with 1 HS-11 only [52]. 
The addition of pharmaceutical active ingredients to the oil phase usually led to bigger droplets of $\mathrm{O} / \mathrm{W}$ microemulsions and broader droplet size distributions [48], due to possible effects on the dispersed phase viscosity and the interfacial tension. The size of dichloromethane droplets increased from $98 \mathrm{~nm}$ to $360 \mathrm{~nm}$ when $20 \mathrm{wt} \%$ flurbiprofen was added to the dispersed phase [45]. On the other hand, the droplet size of trimyristin nanoemulsions was not affected when 5 wt\% ubidecarenone was added to the dispersed phase [51].

\section{Tuning Droplet Size in Premix ME}

Preparation of nanoemulsions by direct ME suffers from low throughputs and droplet size is relatively large compared to the pore size. Premix ME allows smaller droplet sizes than direct ME and has been widely used to prepare nanoemulsions (Table 3). However, premix ME often leads to broader droplet size distribution than direct ME due to less controllable mechanism of droplet disruption based on shear and impact forces in the pores that cause compression, stretching, and deformation of the droplets prior to their break up [81, 82].

Pore size. The droplet size can be reduced by decreasing the pore size, but the effect is less pronounced than in direct $\mathrm{ME}([18,51]$. For single pass at constant shear in the pores: $d_{\text {droplet }}=K^{\prime \prime}\left(d_{\text {pore }}\right)^{n}$, where $n<1$. The $K^{\prime \prime}$ value is higher at lower flux and higher interfacial tension. For medium-chain triglyceride (MCT) emulsions stabilised with sodium dodecyl sulphate, after single pass through an SPG membrane at 9 bar, $d_{\text {droplet }} / d_{\text {pore }}$ was $0.4-1.1$ depending on the dispersed phase concentration (2.5-10 wt\%) and the pore size (100-300 nm) [54]. Therefore, $d_{\text {droplet }} / d_{\text {pore }}$ was 3-9 times smaller than in direct ME.

Membrane wettability. A good wettability of the membrane wall by the continuous phase was essential to produce droplets of medium-chain triglycerides in water with $d_{50}<500 \mathrm{~nm}$ using hydrophilic membranes with a pore size of $200 \mathrm{~nm}$ [83]. After 21 passes, $d_{50}$ varied between $0.15 \mu \mathrm{m}$ and $11 \mu \mathrm{m}$ depending on the membrane and surfactant used (Fig. 7). The most important parameter affecting $d_{50}$ of the extruded emulsions was the contact angle $\theta$ between the surfactant solution and the membrane surface, which was in the range from $17^{\circ}$ to $77^{\circ}$. A low $\theta$ value was found to favour small droplets irrespective of the pore morphology and the viscosity of the dispersed phase. 


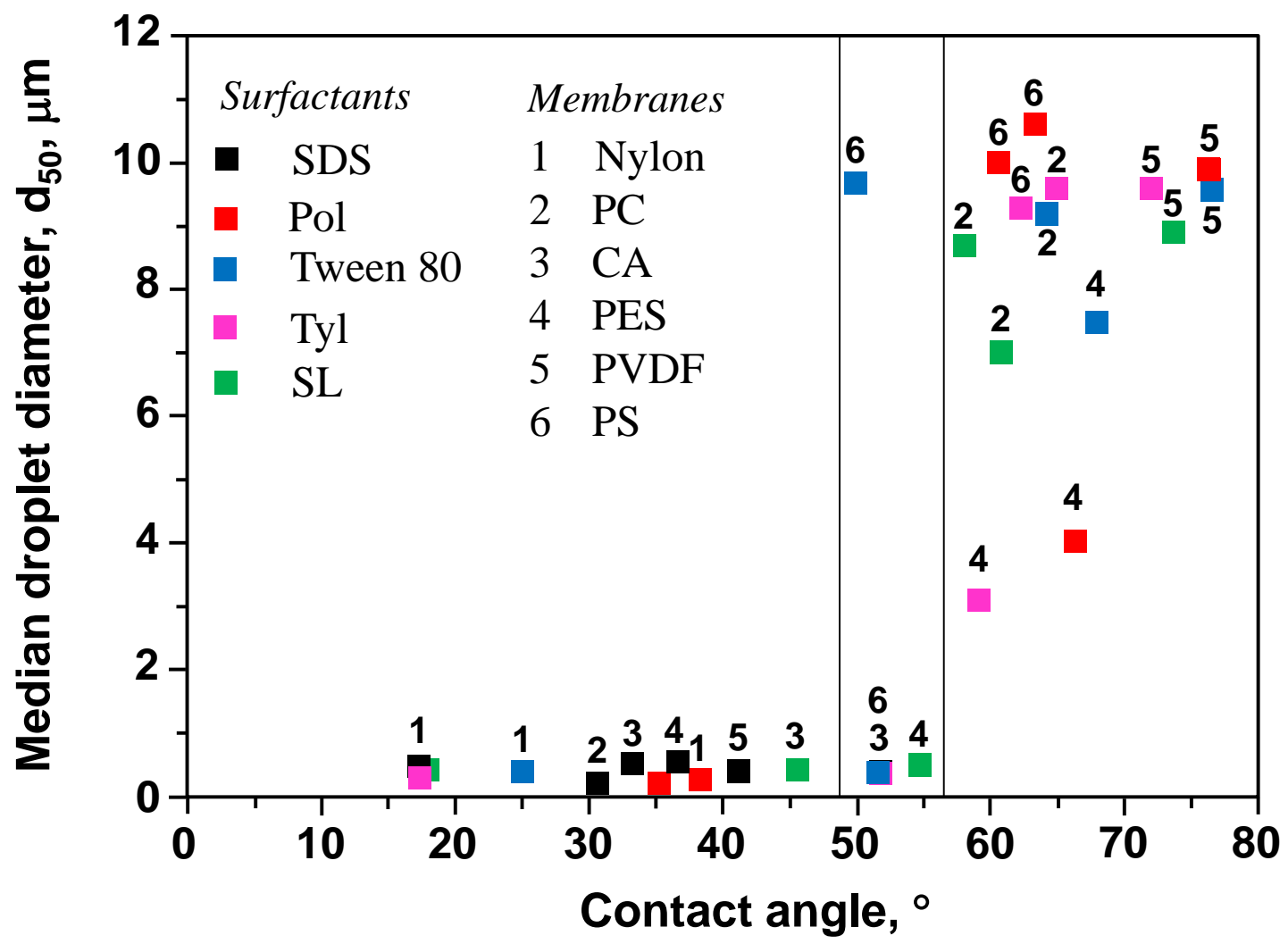

Figure 7. Median droplet sizes of emulsions obtained by extrusion through different syringe filters with a pore size of $200 \mathrm{~nm}$ (21 cycles, transmembrane flow rate: $0.25 \mathrm{~mL} / \mathrm{s}$, dispersed phase: MCT oil; continuous phase: $6.25 \mathrm{wt} \%$ surfactant solution) as a function of the contact angle between the surfactant solution and membrane surface. Each point is a mean of 3 repeated experiments [30].

Based on $d_{50}$ of emulsions containing $20 \mathrm{wt} \%$ of the dispersed phase (medium-chain triglycerides) achieved after 21 extrusions at $25 \mathrm{~cm}^{3} \mathrm{~s}^{-1}$, polymeric membranes were classified into three categories [83]. The first category (polyamide and cellulose acetate) produced monomodal emulsions with $d_{50}<500 \mathrm{~nm}$ using all surfactants (sodium dodecyl sulphate, poloxamer 188, Tween 80, tyloxapol, and sucrose laurate) at $6.25 \mathrm{wt} \%$. The second category (polysulfone, polycarbonate, and polyvinylidene fluoride) produced monomodal emulsions with $d_{50}<500 \mathrm{~nm}$ using sodium dodecyl sulphate only. The third group (polyethersulfone and polyethylene) demonstrated intermediate behaviour. Emulsions with $d_{50}<0.5 \mu \mathrm{m}$ were produced with all membranes and surfactants for $\theta<49^{\circ}$, while $\theta>55^{\circ}$ resulted in $d_{50}>3 \mu \mathrm{m}$ 
for all membranes and surfactants. To confirm that $d_{50}$ critically depends on wetting properties of the membrane, polyethylene and polycarbonate membranes were surface modified with $\mathrm{O}_{2}$ gas plasma to decrease $\theta$ without affecting the pore morphology and smaller droplet sizes were obtained for plasma treated membranes. After 21 passes through a commercial AAM with a pore size of $200 \mathrm{~nm}$, emulsions with $d_{50}<250 \mathrm{~nm}$ were obtained with all surfactants, due to superior hydrophilic properties of this membrane. The smallest $d_{50}$ value of $77 \mathrm{~nm}$ was achieved with sodium dodecyl sulphate [30], but emulsions with even smaller droplet sizes were produced using AAM with a pore size of $100 \mathrm{~nm}$ [83].

Membrane structure. Membrane thickness, porosity, pore interconnectivity, and pore size uniformity are highly relevant in premix ME. At the same transmembrane flux, smaller droplets can be achieved using thicker membrane with more uniform pore sizes. Interconnected and branched pores are often more effective than straight non-interconnected pores, but membranes with high porosity are inefficient even if they contain highly interconnected pores. For example, track-etched polymeric membranes produced emulsions with smaller droplets than polymeric syringe filters with sponge-like morphology [54], probably due to broad size distribution and high porosity $(\varepsilon)$ of syringe filters leading to low and non-uniform shear in their pores. The mean shear stress at the pore walls is given by:

$$
\tau_{w, \text { pore }}=8 \eta_{e} J \zeta /\left(\varepsilon d_{\text {pore }}\right)
$$

where $\eta_{e}$ is the emulsion viscosity, $\varepsilon$ is membrane porosity, $\zeta$ the pore tortuosity, and $J$ the transmembrane flux. Therefore, high membrane porosity leads to small shear stress in the pores. However, track-etched membranes are less effective in droplet disruption than SPG membranes due to their much smaller thickness and shorter residence time of emulsion within the pores [51]. A higher efficiency of SPG membrane at the same pore size in the range of $0.1-0.3 \mu \mathrm{m}$ is so pronounced that smaller droplets were produced after single pass through an SPG membrane than after 21 passes through a tracked-etched polycarbonate membrane. Therefore, irrespective of porosity, thick membranes with highly interconnected and tortuous pores are more effective than thin membranes with straight parallel pores [84]. 
In the case of nickel superalloy membranes, $\gamma^{\prime}$ membranes manufactured by leaching the $\gamma$ phase are more suitable than $\gamma$ membranes to produce emulsions with smaller droplets $(\sim 150$ $\mathrm{nm})$ and monomodal distributions [23].

Pore size uniformity. Highly uniform pore size distribution is not crucial in repeated premix ME due to random pathways of droplets through the membrane [30]. Therefore, a broader pore size distribution of syringe filters can be compensated by larger number of extrusions to produce similar droplet size distributions as with SPG or track-etched membranes.

Number of extrusions. Smaller droplet sizes can be achieved by implementing larger number of extrusions through the membrane [85]. The droplet size and extrusion pressure $(\Delta P)$ reach constant values after sufficient number of passes at constant flux $[8,67]$ with first extrusion leading to the highest reduction in droplet size and pressure drop compared to subsequent extrusions. The number of extrusions required to reach a steady-state droplet size and monomodal droplet size distribution depends on the membrane thickness, pore size uniformity and membrane morphology. Thicker membranes with narrower pore size distribution and branched pores require smaller number of extrusions than thin membranes with broader pore size distribution and non-interconnected pores or highly open porous structure. The smallest number of extrusions is needed for SPG membrane, followed by track-etched membranes, and then syringe filters and nickel superalloy membranes: At constant flux, steady-state droplet size can be achieved after smaller number of passes using track-etched membranes than syringe filters [30] and nickel-based superalloy membranes [23] due to a broad pore size distribution and highly open porous structure in the latter case. For example, a monomodal droplet size distribution of SDS-stabilised emulsions with a median droplet diameter of $320 \mathrm{~nm}$ was achieved after only two passes through a 200-nm track-etched polyethylene membrane [54], while at least 11 extrusions through nickel superalloy membranes were needed to achieve a monomodal size distribution [23].

Premix volume and quality. The pressure drop during injection of premix at $200 \mathrm{~mL} / \mathrm{min}$ through an SPG membrane with a pore size of $0.5 \mu \mathrm{m}$ was found to be constant up to the premix volume of $500 \mathrm{~mL}$ [66], indicating negligible membrane fouling and insignificant accumulation of droplets at the membrane surface. In addition, the resulting droplet size was independent of 
the volume of premix injected $[18,66]$. The droplet size distribution of the final emulsion was independent of the droplet size distribution of the premix after 5 extrusions through polymeric membranes [83]. However, the minimum droplet size of the premix must be larger than the maximum pore size of the membrane.

Flux and pressure. At constant flow rate through the membrane, the extrusion pressure was reduced after each pass until a constant pressure difference was reached [54]. It can be explained by the fact that smaller droplets are less deformed and disrupted as they flow through the pores which leads to smaller energy dissipation. Pressure drop in premix ME is a consequence of flow resistances in the membrane system and droplet disruption [66, 67]. Higher pressures are needed for extrusions through thicker membranes and at higher flow rates. Ni superalloy membranes required higher extrusion pressures than track-etched polyethylene membrane due to 15-30 times higher thickness [23]. Emulsions with smaller droplets were produced at higher extrusion pressures, due to higher flux, according to Eq. (1) [66, 67]. The extrusion pressure of 3 bar was enough to produce SDS-stabilised emulsion droplets with a median diameter of $\sim 200$ $\mathrm{nm}$ after 21 passes through track-etched polycarbonate membrane with a pore size of $200 \mathrm{~nm}$ [54]. The extrusion pressures up to 60 bar were needed to produce an $\mathrm{O} / \mathrm{W}$ nanoemulsion stabilised with ethylhexyl palmitate, Tween 20, and Span 80, with a median droplet diameter of $280 \mathrm{~nm}$ using an SPG membranes with a pore size of $200 \mathrm{~nm}$ [66].

Viscosities of bulk phases and interfacial tension. As droplets are moving along the pores driven by the pressure difference, they are stretched into cylinders of radius $R_{c y l}$, surrounded by a thin "lubricating layer" of the continuous phase. The thickness of this lubricating layer is $R_{\text {pore }}\left(\eta_{c} U_{\text {drop }} / \gamma\right)^{2 / 3}$, where $\eta_{c}$ is the viscosity of the continuous phase and $U_{d r o p}$ the velocity of liquid cylinders. Droplets are disintegrated into two pieces if the thickness of the lubricating layer is sufficiently large that $R_{c y l}<\lambda /(2 \pi)$, where $\lambda$ is the the Plateau-Rayleigh wavelength. Therefore, the resulting droplet size decreases with decreasing the interfacial tension and with increasing the viscosity of the continuous phase [85]. The effect of the dispersed phase viscosity on the final droplet size was found to be negligible [85].

Surfactant concentration. The effect of surfactant concentration on droplet size distribution was investigated for both SPG and polymeric membranes $[18,66]$. In both cases, a decrease in 
droplet size was observed when the surfactant concentration was reduced, but the effect was much more pronounced for smaller membrane pore sizes [18]. The surfactant concentration affects the pressure drop across the membrane due to effects on the viscosity of the continuous phase and interfacial tension. Using SPG membrane with a pore size of $500 \mathrm{~nm}$, a decrease in pressure was observed at constant flux when the total surfactant concentration was increased from $2.5 \mathrm{wt} \%$ to $15 \mathrm{wt} \%$ in spite of significant increase in the emulsion viscosity, due to smaller amount of energy needed for droplet disruption [66]. Using polycarbonate membrane with a pore size of 50-200 nm, a decrease in pressure was observed at constant flux with a decreasing concentration of surfactant [18]. Here, surfactant concentration predominantly affected the viscosity of the continuous phase. The amount of surfactant required to achieve a monomodal distribution is related to the interfacial area, which depends on the particle size distribution and the dispersed phase concentration.

\section{Preparation of Drug Delivery Systems from Microemulsions}

Due to gentle processing and small sample volumes, microemulsions produced by ME were used to encapsulate lipophilic drugs (Table 1A-E). Solid formulations were prepared using dichloromethane in the dispersed phase as a volatile solvent with high drug solubility and hydrophilic excipients such as dextran, calcium silicate or polyvinylpyrrolidone in the aqueous phase $[46,86,87]$. The emulsions were spray dried to evaporate water and dichloromethane and produce solid drug delivery systems for Class II drugs. Hydrophilic (Class III) drugs were encapsulated within inner water phase of $\mathrm{W}_{1} / \mathrm{O} / \mathrm{W}_{2}$ micro/nano-emulsions [50, 52].

\section{Production of Nanoparticles from Nanoemulsions}

Transformation of liquid droplets into solid nanoparticles (NPs) allows to minimise leakage of encapsulated active ingredients (due to lower diffusion rates in solids than in liquids) and increase size stability of the dispersed phase $[88,89]$. Solid nanostructures can be formed by ionic or covalent crosslinking [90, 91], solvent evaporation [92], melt solidification [18], UVcuring [38], and implementation of redox reactions inside droplets [62]. 
Nanogels were produced by crosslinking hydrophilic polymers within aqueous nanodroplets produced via hydrophobic SPG membrane. Crosslinking of chitosan chains was achieved with glutaraldehyde [90, 91, 93], while alginate was crosslinked with calcium ions [94]. Nanogels are useful drug delivery systems because they can adsorb large amount of aqueous phase [95, 96] and sense changes in environmental conditions to release their cargos [97].

Solid Lipid NPs were prepared by ME at the temperatures which are at least several ${ }^{\circ} \mathrm{C}$ higher than the melting point of the lipids and the resulting droplets were solidified by rapid cooling. In most cases, emulsification temperature was between 65 and $80^{\circ} \mathrm{C}$ and the membranes used were SPG membranes [51, 98] and polycarbonate track-etched membranes [18].

Synthetic Biodegradable Polymeric NPs loaded with Class II drugs were produced from O/W nanoemulsions using ME and solvent evaporation [99]. Typically, droplets are composed of a volatile organic solvent and a drug and the continuous phase is an aqueous solution of polyvinyl alcohol [89, 100, 101]. Antigen-coated PLA NPs were produced by immersing the produced PLA NPs in an antigen solution [101]. Polymeric NPs loaded with Class III drugs were prepared from $\mathrm{W}_{1} / \mathrm{O} / \mathrm{W}_{2}$ nanoemulsions using two-step emulsification procedure (ultrasonication and ME) followed by solvent evaporation [102, 103]. $\mathrm{W}_{1} / \mathrm{O} / \mathrm{W}_{2}$ nanoemulsions produced by $\mathrm{ME}$ can be used to encapsulate simultaneously a Class III drug (in aqueous cores) and a Class II drug (in hydrophobic polymer shells) [104]. The fabrication process is explained in more details elsewhere [99, 104].

Metallic NPs. Magnetite NPs were prepared by dispersing a solution of iron (III) 2ethylhexanoate in hexane via an anodic alumina membrane and adding a $\mathrm{NH}_{4} \mathrm{OH}$ solution into the produced emulsion [62]. Nanoclusters composed of magnetite NPs coated with a thin silica layer were produced by ME, solvent evaporation and sol-gel processing [105].

Inorganic and metal oxide $\mathrm{NPs}$. $\mathrm{SiO}_{2} \mathrm{NPs}$ were produced by solidification of nanodroplets of sodium silicate solution prepared using anodic alumina membrane [42]. Nanoclusters composed of $\mathrm{SiO}_{2}, \mathrm{NbO}$, SeO, or $\mathrm{TiO}_{2} \mathrm{NPs}$ were produced by emulsifying various aqueous dispersions of inorganic oxide NPs into the organic phase via a 130-nm anodic alumina membrane, followed by drying the prepared W/O nanoemulsions [106]. 


\section{Conclusions}

Membrane emulsification is a viable method to produce micro/nano- emulsions and solid nanoparticles with a monomodal distribution and tuneable particle size. Due to extremely low interfacial tension, microemulsions can be prepared using membranes with micron-sized pores. There is no benefit of using membranes with $d_{50}<0.3 \mu \mathrm{m}$ (which are indispensable to prepare nanoemulsions), but the pore size should not be above $2.5 \mu \mathrm{m}$. In spite of the common notion that microemulsions are formed by spontaneous emulsification, there are many experimental evidences suggesting that a certain degree of control over the droplet size and size distribution can be achieved by emulsifying liquids through a membrane.

Nanoemulsions (submicron emulsions for the purpose of this review) can be prepared by direct ME using membranes with a pore size at least several times smaller than $1 \mu \mathrm{m}$. The maximum pore size of SPG membrane for this purpose is about $0.2 \mu \mathrm{m}$ and $d_{50} / d_{\text {pore }}$ is usually between 2.8 and 3.5. The minimum pore size of SPG membrane is $0.1 \mu \mathrm{m}$, which is a significant limiting factor to prepare nanoemulsions with very small droplet sizes by direct ME. The most suitable membrane for preparation of nanoemulsions by direct ME is anodic alumina membrane (AAM), because it can be manufactured with a pore size of $5 \mathrm{~nm}$ and with a thickness of few tens of nanometres enabling $d_{50}$ values below $100 \mathrm{~nm}$.

Premix ME allows up to 10 times smaller droplets than direct ME but usually on the account of broader droplet size distribution. Track-etched polymeric membranes are less efficient in disrupting droplets than SPG membranes, due to their non-interconnected straight pores and short residence time of emulsion due to small membrane thickness. In most cases, a single pass through SPG membrane was enough to obtain sufficiently small droplet size, while in the case of tracked-etched polycarbonate membranes multiple extrusions were needed in most cases. The droplet size in premix ME critically depends on wettability of the membrane surface by the continuous phase. The better the wettability of the membrane wall by the continuous phase liquid, the smaller the droplet size that can be acheived. The contact angle between the aqueous surfactant solution and a membrane surface must be less than $49^{\circ}$ to safely produce $\mathrm{O} / \mathrm{W}$ 
nanoemulsions with $d_{50}<500 \mathrm{~nm}$ by repeated extrusions through polymeric membrane filters. The contact angle can be tailored by plasma treatment.

$\mathrm{O} / \mathrm{W}$ and $\mathrm{W} / \mathrm{O} / \mathrm{W}$ microemulsions prepared by $\mathrm{ME}$ were used as nanocarriers for enhancement of solubility and membrane permeability of BCS class II and class III drugs, respectively. The prepared microemulsions were transformed into solid drug delivery systems by spray drying.

Nanodroplets prepared by ME can be solidified by crosslinking, solvent evaporation, melt cooling, UV-curing and via redox and sol-gel reactions. The advantages of ME over conventional emulsification techniques are: (i) tuneable droplet / particle sizes with narrow size distributions which allows predictable release patterns and properties of emulsions; (ii) high encapsulation efficiency of entrapped materials; (iv) low energy input with minimal thermal and shear degradation of materials; and (v) small sample volumes (which could be also a limiting factor). New developments in the fabrication of nanoporous membranes, new membrane emulsification techniques, and public attitudes towards sustainable processing and energy-efficient technologies will likely lead to increased utilisation of membranes for the production of solid/liquid nanodispersions.

\section{Abbreviations}

Chemicals/materials: AOT, docusate sodium salt; Brij ${ }^{\circledR} 35$, polyethylene glycol dodecyl ether; CA, cellulose acetate; CATO, glyceryl behenate; CR-310, condensed ricinoleic acid tetraglycerin ester; DCM, dichloromethane; DOX, doxorubicin; Gelucire 44/14, lauroyl polyoxylglycerides; HS-9, HS-11, stearyl hexaglycerides; L-7D, lauric acid decaglycerol ester; Labrasol ${ }^{\circledR}$, lauroyl polyoxylglycerides; Lipoid S100, soybean phospholipids manufactured by Lipoid GmbH; MCE, mixed cellulose ester; MCT, medium-chain triglycerides; PBS, phosphate-buffered saline; PC, polycarbonate; PE, polyester; PES, polyethersulfone; PGPR, polyglycerol polyricinoleate; PG10-L, polyglyceryl-10-laurate; PLA, polylactic acid; PLGA, poly(lactic-co-glycolic acid); Pol, poloxamer 188 (Pluronic ${ }^{\circledR}$ F68); PS, polysulfone; PTFE, polytetrafluoroethylene; PVA, polyvinyl alcohol; PVDF, polyvinylidene fluoride; SBO, soybean oil; SDS, sodium dodecyl sulphate; SL, sucrose laurate; Span 20, sorbitan monolaurate; Span 80, sorbitan monooleate; SPG, Shirasu porous 
glass; S-24D, S-28D, stearic acid decaglycerol esters; TEOS, tetraethylorthosilicate; TGPR, tetraglycerol polyricinoleate; TM, trimyristin; Transcutol HP, highly purified diethylene glycol monoethyl ether; Tween 20, polyoxyethylene (20) sorbitan monolaurate; Tween 80, polyoxyethylene (20) sorbitan monooleate; Tyl, tyloxapol.

Emulsions/dispersions: O/W, oil-in-water; O/W/O, oil-in-water-in-oil; W/O, water-in-oil, W/O/W, water-in-oil-in-water.

Acronyms: HLB, hydrophile-lipophile balance; ME, membrane emulsification; NP, nanoparticle; SEM, scanning electron microscopy.

\section{Symbols}

$\begin{array}{ll}d_{50} & \text { Diameter of the drop that } 50 \% \text { of a sample's volume is smaller than, } \mathrm{m} \\ d_{\text {droplet }} & \text { Droplet diameter, } \mathrm{m} \\ d_{\text {pore }} & \text { Pore diameter, } \mathrm{m} \\ J & \text { Transmembrane flux, } \mathrm{m}^{3} \mathrm{~m}^{-2} \mathrm{~s}^{-1} \\ K^{\prime} & \text { Proportionality constant between pore size and droplet size in direct ME, / } \\ K^{\prime \prime} & \text { Constant in the equation for droplet size in premix ME, } \mathrm{m}^{-\mathrm{n}} \\ n & \text { Exponent in the equation for droplet size in premix ME, / } \\ P & \text { Pressure, Pa } \\ R_{c y l} & \text { Radius of droplet cylinder } \\ R_{p o r e} & \text { Pore radius, } \mathrm{m} \\ U & \text { Fluid velocity, } \mathrm{m} \mathrm{s}^{-1} \\ \lambda & \text { Plateau-Rayleigh wavelength, } \mathrm{m} \\ \gamma & \text { Interfacial tension between water and oil phase, } \mathrm{N} \mathrm{m}^{-1} \\ \varepsilon & \text { Membrane porosity, / } \\ \phi & \text { Volume fraction of dispersed phase, / } \\ \eta & \text { Viscosity, Pa s } \\ \tau_{w} & \text { Pore tortuosity, / } \\ & \text { Shear stress on membrane surface, Pa }\end{array}$




\section{Subscripts}

c Continuous phase

d Dispersed phase

drop Droplet

e Emulsion 


\section{References}

[1] Piacentini, E., Drioli, E., Giorno, L., 2014. Membrane emulsification technology: Twenty-five years of inventions and research through patent survey, J. Membr. Sci. 468, $310-422$.

[2] Nakashima, T., Shimizu, M., Kukizaki, K., 2000. Particle control of emulsion by membrane emulsification and its applications. Adv. Drug Deliv. Rev. 45, 47-56.

[3] Kosvintsev, S.R., Gasparini, G., Holdich, R.G., 2008. Membrane emulsification: droplet size and uniformity in the absence of surface shear. J. Membr. Sci. 313, 182-189.

[4] Kukizaki, M., 2009. Shirasu porous glass (SPG) membrane emulsification in the absence of shear flow at the membrane surface: Influence of surfactant type and concentration, viscosities of dispersed and continuous phases, and transmembrane pressure. J. Membr. Sci. 327, 234-243.

[5] Kukizaki, M., Goto, M., 2009. A comparative study of SPG membrane emulsification in the presence and absence of continuous-phase flow. J. Chem Eng. Jpn. 42, 520-530.

[6] Suzuki, K., Shuto, I., Hagura, Y., 1996. Characteristics of the membrane emulsification method combined with preliminary emulsification for preparing corn oil-in-water emulsions. Food Sci. Technol. Int. Tokyo. 2, 43-47.

[7] Sawalha, H., Sahin, S., Schroën, K., 2016. Preparation of polylactide microcapsules at a high throughput with a packed-bed premix emulsification system. J. Appl. Polym. Sci. 133, 43536.

[8] Laouini, A., Charcosset, C., Fessi, H., Schroen, K., 2014. Use of dynamic membranes for the preparation of vitamin E-loaded lipid particles: An alternative to prevent fouling observed in classical cross-flow emulsification. Chem. Eng. J. 236, 498-505.

[9] Mugabi, J., Naohiro, K., Hiroki, Y., Miki, M., Igura, N., Shimoda, M., 2019. Preparation of small droplet size monodispersed emulsions at high production rate by continuous intramembrane premix emulsification method. J. Chem. Eng. Jpn. 52, 259-266.

[10] Kukizaki, M., Goto, M., 2008. Demulsification of water-in-oil emulsions by permeation through Shirasu-porous-glass (SPG) membranes. J. Membr. Sci. 322, 196-203.

[11] Suzuki, K., Fujiki, I., Hagura, Y., 1999. Preparation of high concentration of O/W and W/O emulsions by the membrane phase inversion emulsification using PTFE membranes. Food Sci. Technol. Int. Tokyo. 5, 234-238. 
[12] Mi, Y., Zhou, W., Li, Q., Gong, F., Zhang, R., Ma, G., Su, Z., 2015. Preparation of waterin-oil emulsions using a hydrophobic polymermembrane with 3D bicontinuous skeleton structure. J. Membr. Sci. 490, 113-119.

[13] Cheng, C.J., Chu, L.Y., Xie, R., Wang, X.W., 2008. Preparation of highly monodisperse W/O emulsions with hydrophobically modified SPG membranes. Chem. Eng. Technol. 31, 377-383.

[14] Vladisavljević, G.T., Wang, B., Dragosavac, M.M., Holdich, R.G., 2004. Production of food-grade multiple emulsions with high encapsulation yield using oscillating membrane emulsification. Colloids Surf. A. 458, 78-84.

[15] Karbstein, H., Schubert H., 1995. Developments in the continuous mechanical production of oil-water macro-emulsions. Chem. Eng. Process. 34, 205-211.

[16] Alliod, O., Almouazen, E., Nemer, G., Fessi, H., Charcosset, C., 2019. Comparison of three processes for parenteral nanoemulsion production: ultrasounds, microfludizer and premix membrane emulsification. J. Pharm. Sci., in press.

[17] Othman, R., Vladisavljević, G.T., Shahmohamadi, H., Nagy, Z.K., Holdich, R.G., 2016. Formation of size-tuneable biodegradable polymeric nanoparticles by solvent displacement method using micro-engineered membranes fabricated by laser drilling and electroforming. Chem. Eng. J. 304, 703-713.

[18] Joseph, S., Bunjes, H. 2012. Preparation of nanoemulsions and solid lipid nanoparticles by premix membrane emulsification. J. Pharm. Sci. 2012, 2479-2489.

[19] Vladisavljević, G.T., Shimizu, M., Nakashima, T., 2005. Permeability of hydrophilic and hydrophobic Shirasu-porous-glass (SPG) membranes to pure liquids and its microstructure. J. Membr. Sci. 250, 69-77.

[20] Chen, Y., Zhao, Z., Dai, J., Liu, Y., Ma, H., Nie, R., 2008. Etching characteristic for tracks of multicharged ions in polymer. Radiation Measurements. 43, S111 - S115.

[21] He, D., Ulbricht, M. 2006. Surface-selective photo-grafting on porous polymer membranes via a synergist immobilization method. J. Mater. Chem. 16, 1860-1868.

[22] Poinern, G.E.J., Le, X.T., Hager, M., Becker, T., Fawcett, D. 2013. Electrochemical synthesis, characterisation, and preliminary biological evaluation of an anodic aluminium oxide membrane with a pore size of 100 nanometres for a potential cell culture substrate. Am. J. Biomed. Eng. 3, 119-131. 
[23] Kohnke, M., Finke, J.H., Kwade, A., Rösler, J., 2018. Investigation of nanoporous superalloy membranes for the production of nanoemulsions. Metals. 8: 361.

[24] Kukizaki, M., Nakashima, T., 2004. Acid leaching process in the preparation of porous glass membranes from phase-separated glass in the $\mathrm{Na}_{2} \mathrm{O}-\mathrm{CaO}-\mathrm{MgO}-\mathrm{Al}_{2} \mathrm{O}_{3}-\mathrm{B}_{2} \mathrm{O}_{3}-\mathrm{SiO}_{2}$ system. Membrane. 29, 301-308.

[25] Kukizaki, M., 2010. Large-scale production of alkali-resistant Shirasu porous glass (SPG) membranes: Influence of $\mathrm{ZrO}_{2}$ addition on crystallization and phase separation in $\mathrm{Na}_{2} \mathrm{O}-$ $\mathrm{CaO}-\mathrm{Al}_{2} \mathrm{O}_{3}-\mathrm{B}_{2} \mathrm{O}_{3}-\mathrm{SiO}_{2}$ glasses; and alkali durability and pore morphology of the membranes. J. Membr. Sci. 360, 426-435.

[26] Vladisavljević, G.T., Kobayashi, I., Nakajima, M., Williams, R.A., Shimizu, M. and Nakashima, T., 2007. Shirasu Porous Glass membrane: Characterisation of microstructure by high resolution x-ray microtomography and visualisation of droplet formation in real time. J. Membr. Sci. 302, 243-253.

[27] Kukizaki, M., 2009. Relation between salt rejection and electrokinetic properties on Shirasu porous glass (SPG) membranes with nano-order uniform pores. Sep. Sci. Technol. 69, 87-96.

[28] Kukizaki, M., Wada, T., 2008. Effect of the membrane wettability on the size and size distribution of microbubbles formed from Shirasu-porous-glass (SPG) membranes. Colloids Surf., A. 317, 146-154.

[29] P. Apel, 2001. Track-etching technique in membrane technology. Radiat. Meas. 34, 559566.

[30] Gehrmann, S., Bunjes, H., 2018. Influence of membrane material on the production of colloidal emulsions by premix membrane emulsification. Eur. J. Pharm. Biopharm. 126, $140-148$.

[31] Liu, F., Hashim, N.A., Liu, Y., Abed, M.R.M., Li, K., 2011. Progress in the production and modification of PVDF membranes. J. Membr. Sci. 375, 1-27.

[32] Gehrmann, S., Bunjes, H., 2016. Preparation of lipid nanoemulsions by premix membrane emulsification with disposable materials. Int. J. Pharm. 511, 741-744.

[33] Nazir, A., Schroën, K., Boom, R., 2011. High-throughput premix membrane emulsification using nickel sieves having straight-through pores. J. Membr. Sci. 383, $116-123$. 
[34] Egidi, E., Gasparini, G., Holdich, R.G., Vladisavljević, G.T., Kosvintsev, S.R., 2008. Membrane emulsification using membranes of regular pore spacing: Droplet size and uniformity in the presence of surface shear. J. Membr. Sci. 323, 414-420.

[35] van Rijn, C., van der Wekken, M., Nijdam, W., Elwenspoek, M., 1997. Deflection and maximum load of microfiltration membrane sieves_made with silicon micromachining. J. Microelectromech. Syst. 6, 48-54.

[36] Kobayashi, I., Vladisavljević, G.T., Uemura, K., Nakajima, M., 2011. CFD analysis of microchannel emulsification: Droplet generation process and size effect of asymmetric straight flow-through microchannels. Chem. Eng. Sci. 66, 5556-5565.

[37] Vladisavljević, G.T., Williams, R.A., 2006. Manufacture of large uniform droplets using rotating membrane emulsification. J. Colloid Interface Sci. 299, 396-402.

[38] Yanagishita, T., Fujimura, R., Nishio, K., Masuda, H., 2010. Fabrication of monodisperse polymer nanoparticles by membrane emulsification using ordered anodic porous alumina. Langmuir. 26, 1516-1519.

[39] Yanagishita, T., Kato, A., Masuda, H., 2017. Preparation of ideally ordered through-hole anodic porous alumina membranes by two-layer anodization. Jpn. J. Appl. Phys. 56, 035202.

[40] Lee, K.P., Mattia, D., 2013. Manufacturing of nanoemulsions using nanoporous anodized alumina membranes: experimental investigation and process modelling. Ind. Eng. Chem. Res. 52, 14866-14874.

[41] Belwalkar, A., Grasing, E., Van Geertruyden, B., Huang, Z., Misiolek, W. Z., 2008. Effect of processing parameters on pore structure and thickness of anodic aluminum oxide (AAO) tubular membranes. J. Membr. Sci. 319, 192-198.

[42] Yanagishita, T., Tomabechi, Y., Nishio, K., Masuda, H., 2004. Preparation of monodisperse $\mathrm{SiO}_{2}$ nanoparticles by membrane emulsification using ideally ordered anodic porous alumina. Langmuir. 20, 554-555.

[43] McClements, D.J., 2012. Nanoemulsions versus microemulsions: terminology, differences, and similarities. Soft Matter, 8, 1719-1729.

[44] Mason, T.G., Wilking, J.N., Meleson, K, Chang, C.B., Graves, S.M., 2016. Nanoemulsions: formation, structure, and physical properties. J. Phys.: Condens. Matter. 18, R635. 
[45] Oh, D.H., Balakrishnan, P., Oh, Y.K., Kim, D.D., Yong, C.S., Choi, H.G., 2011. Effect of process parameters on nanoemulsion droplet size and distribution in SPG membrane emulsification. Int. J. Pharm., 404, 191-197.

[46] Choi, Y.K., Poudel, B.K., Marasini, N., Yang, K.Y., Kim, J.W., Kim, J.O., Choi, H.G., Yong, C.S., 2012. Enhanced solubility and oral bioavailability of itraconazole by combining membrane emulsification and spray drying technique. Int. J. Pharm. 434, $264-271$.

[47] Pradhan, R., Lee, D.W., Choi, H.G., Yong, C.S., Kim, J.O., 2013. Fabrication of a uniformly sized fenofibrate microemulsion by membrane emulsification. J. Microencapsulation. 30, 42-48.

[48] Laouini, A., Fessi, H., Charcosset, C., 2012. Membrane emulsification: A promising alternative for vitamin E encapsulation within nano-emulsion. J. Membr. Sci. 423-424, 85-96.

[49] Adamczak, M., Kupiec, A., Jarek, E., Szczepanowicz, K., Warszyński, P., 2014. Preparation of the squalene-based capsules by membrane emulsification method and polyelectrolyte multilayer adsorption. Colloids Surf., A. 462, 147-152.

[50] Pradhan, R., Kim, Y.I., Jeong, J.H., Choi, H.G., Yong, C.S., Kim, J.O., 2014. Fabrication, characterization and pharmacokinetic evaluation of doxorubicin-loaded water-in-oil-inwater microemulsions using a membrane emulsification technique. Chem. Pharm. Bull. 62, 875-882.

[51] Joseph, S., Bunjes, H., 2014. Evaluation of Shirasu Porous Glass (SPG) membrane emulsification for the preparation of colloidal lipid drug carrier dispersions. Eur. J. Pharm. Biopharm. 87, 178-186.

[52] Koga, K., Takarada, N., Takada, K., 2010. Nano-sized water-in-oil-in-water emulsion enhances intestinal absorption of calcein, a high solubility and low permeability compound. Eur. J. Pharm. Biopharm. 74, 223-232.

[53] Medina-Llamas, M., Mattia, D., 2017. Production of nanoemulsions using anodic alumina membranes in a stirred-cell setup. Ind. Eng. Chem. Res. 56, 7541-7550.

[54] Gehrmann, S., Bunjes, H., 2016. Instrumented small scale extruder to investigate the influence of process parameters during premix membrane emulsification. Chem. Eng. J. 284, 716-723. 
[55] Albert, K., Koris, A., Gaspar, I., Racz, G., Vatai, G., 2014. Production of microemulsion by membrane emulsification: comparison of empty ceramic tube membrane and membrane equipped with static turbulence promoters. Acta Aliment. 43, 1-8.

[56] Piacentini, E., Drioli, E., Giorno, L., 2013. Pulsed back-and-forward cross-flow batch membrane emulsification with high productivity to obtain highly uniform and concentrate emulsions. J. Membr. Sci. 453, 119-125.

[57] Holdich, R.G., Dragosavac, M., Vladisavljević, G.T., Piacentini, E., 2013. Continuous membrane emulsification with pulsed (oscillatory) flow. Ind. Eng. Chem. Res. 52, $507-515$.

[58] Agner, T., Zimmermann, A., Di Luccio, M., de Araújo, P.H.H., Sayer, C., 2017. Monomer-in-water miniemulsions by membrane emulsification. Chem. Eng. Process. 120, 251-257.

[59] Dowding, P.J., Goodwin, J.W., Vincent, B., 2001. Production of porous suspension polymer beads with a narrow size distribution using a crossflow membrane and a continuous tubular reactor. Colloids Surf., A. 180. 301-309.

[60] Vladisavljević, G.T., Lambrich, U., Nakajima, M., Schubert, H., 2004. Production of O/W emulsions using SPG membranes, ceramic $\alpha$-aluminium oxide membranes, microfluidizer and a silicon microchannel plate - a comparative study. Colloids Surf., A. 232. 199-207.

[61] Balbach, S., Korn, C., 2004. Pharmaceutical evaluation of early development candidates “the 100 mg-approach”. Int. J. Pharm. 275, 1-12.

[62] Medina-Llamas, M., Mattia, D., 2019. Semi-continuous production of iron oxide nanoparticles via membrane emulsification. Appl. Surf. Sci. 463, 504-512.

[63] Dragosavac, M.M., Holdich, R.G., Vladisavljević, G.T., Sovilj, M.N., 2012. Stirred cell membrane emulsification for multiple emulsions containing unrefined pumpkin seed oil with uniform droplet size. J. Membr. Sci. 392-393, 122-129.

[64] Schadler, V, Windhab, E.J., 2006. Continuous membrane emulsification by using a membrane system with controlled pore distance. Desalination. 189, 130-135.

[65] Silva, P.S., Dragosavac, M.M., Vladisavljević, G.T., Bandulasena, H.C.H., Holdich, R.G., 2013. Azimuthally oscillating membrane emulsification for controlled droplet production. AIChE J. 61, 3607-3615. 
[66] Alliod, O., Messager, L., Fessi, H., Dupin, D., Charcosset, C., 2018. Preparation of oilin-water nanoemulsions at large-scale using premix membrane emulsification and Shirasu Porous Glass (SPG) membranes. Colloids Surf., A. 557, 76-84.

[67] Vladisavljević, G.T., Shimizu, M., Nakashima, T., 2004. Preparation of monodisperse multiple emulsions at high production rates by multi-stage premix membrane emulsification. J. Membr. Sci. 244, 97-106.

[68] Vladisavljević, G.T., Shimizu, M., Nakashima, T., 2006. Production of multiple emulsions for drug delivery systems by repeated SPG membrane homogenization: Influence of mean pore size, interfacial tension and continuous phase viscosity. J. Membr. Sci., 284, 373-383.

[69] Vladisavljević, G.T., Surh, J., McClements, D.J., 2006. Effect of emulsifier type on droplet disruption in repeated Shirasu porous glass membrane homogenization. Langmuir. 22, 4526-4533.

[70] Olson, F., Hunt, C.A., Szoka, F.C., 1979. Preparation of liposomes of defined size distribution by extrusion through polycarbonate membranes. Biochim. Biophys. Acta. $557,9-23$.

[71] van der Graaf, S., Nisisako, T., Schroën, C.G.P.H., van der Sman, R.G.M., Boom, R.M., 2006. Lattice Boltzmann simulations of droplet formation in a T-shaped microchannel. Langmuir. 22, 4144-4152.

[72] Sugiura, S., Nakajima, M., Kumazawa, N., Iwamoto, S., Seki, M., 2002. Characterization of spontaneous transformation-based droplet formation during microchannel emulsification. J. Phys. Chem. B. 106, 9405-9409.

[73] Vladisavljević, G.T., Kobayashi, I., Nakajima, M., 2011. Effect of dispersed phase viscosity on maximum droplet generation frequency in microchannel emulsification using asymmetric straight-through channels. Microfluid. Nanofluid. 10, 1199-1209.

[74] Kukizaki, M., Goto, M., 2007. Preparation and evaluation of uniformly sized solid lipid microcapsules using membrane emulsification. Colloids Surf., A. 293, 87-94.

[75] Yang, K.Y., Hwang, D.H., Yousaf, A.M., Kim, D.W., Shin, Y.J., Bae, O.N., Kim, Y.I., Kim, J.O., Yong, C.S., Choi, H.G., 2013. Silymarin-loaded solid nanoparticles provide excellent hepatic protection: physicochemical characterization and in vivo evaluation. Int. J. Nanomed. 8, 3333-3343. 
[76] Vladisavljević, G.T., 2018. Preparation of nanoemulsions by membrane emulsification. In Jafari, S.M., McClements, J.D. (eds.), Nanoemulsions: Formulation, Applications, and Characterization, London: Academic Press, 287-346.

[77] Schröder, V., Behrend, O., Schubert, H., 1998. Effect of dynamic interfacial tension on the emulsification process using microporous, ceramic membrane. J. Colloid Interface Sci. 202, 334-340.

[78] van der Graaf, S., Schroën, C.G.P.H., Van der Sman, R.G.M., Boom, R.M., 2004. Influence of dynamic interfacial tension on droplet formation during membrane emulsification. J. Colloid Interface Sci. 277, 456-463.

[79] Nakashima, T., Shimizu, M., Kukizaki M., 1993. Effect of surfactant on production of monodispersed O/W emulsion in membrane emulsification. Kag. Kog. Ronbunshu. 19, 991-997.

[80] Surh, J., Jeong, Y.G., Vladisavljević, G.T., 2008. On the preparation of lecithin-stabilized oil-in-water emulsions by multi-stage premix membrane emulsification. J. Food Eng. 89, 164-170.

[81] van der Zwan, E., Schroën, K., van Dijke, K., Boom, R., 2006. Visualization of droplet break-up in pre-mix membrane emulsification using microfluidic devices. Colloids Surf. A. 277, 223-229.

[82] Nazir, A., Schroën, K., Boom, R., 2010. Premix emulsification: A review. J. Membr. Sci. $362,1-11$.

[83] Gehrmann, S., Bunjes, H., 2017. Preparation of Nanoemulsions by premix membrane emulsification: Which parameters have a significant influence on the resulting particle size? J. Pharm. Sci. 106, 2068-2076.

[84] Zhou, Q.Z., Ma, G.H., Su, Z.G., 2009. Effect of membrane parameters on the size and uniformity in preparing agarose beads by premix membrane emulsification. J. Membr. Sci. 326, 694-700.

[85] Alliod, O., Messager, L., Fessi, H., Dupin, D., Charcosset, C., 2019. Influence of viscosity for oil-in-water and water-in-oil nanoemulsions production by SPG premix membrane emulsification. Chem. Eng. Res. Des. 142, 87-99.

[86] Mustapha, O., Kim, K.S., Shafique, S., Kim, D.S., Jin, S.G., Seo, Y.G., Youn, Y.S., Oh, K.T., Lee, B.J., Park, Y.J., Yong, C.S., Kim, J.O., Choi, H.G., 2017. Development of 
novel cilostazol-loaded solid SNEDDS using a SPG membrane emulsification technique: Physicochemical characterization and in vivo evaluation. Colloids Surf. B. 150, 216-222.

[87] Oh, D.H., Din, F.U., Kim, D.W., Kim, J.O., Yong, C.S., Choi, H.G., 2013. Flurbiprofenloaded nanoparticles prepared with polyvinylpyrrolidone using Shirasu porous glass membranes and a spray-drying technique: nanosized formation and improved bioavailability. J. Microencapsulation. 30, 674-680.

[88] Pellegrino, J., Schulte, L.R., De la Cruz, J., Stoldt, C., 2017. Membrane processes in nanoparticle production. J. Membr. Sci. 522, 245-256.

[89] Vladisavljević, G.T., 2015. Structured microparticles with tailored properties produced by membrane emulsification. Adv. Colloid Interface Sci. 225, 53-87.

[90] Lv, P.P., Wei, W., Gong, F.L., Zhang, Y.L., Zhao, H.Y., Lei, J.D., Wang, L.Y., Ma, G.H., 2009. Preparation of uniformly sized chitosan nanospheres by a premix membrane emulsification technique. Ind. Eng. Chem. Res. 48, 8819-8828.

[91] Ma, G.H., Yang, J., Lv, P.P., Wang, L.Y., Wei, W., Tian, R., Wu, J., Su, Z.G., 2010. Preparation of uniform microspheres and microcapsules by modified emulsification process. Macromol. Symp. 288, 41-48.

[92] Doan, T.V.P., Couet, W., Olivier, J.C., 2011. Formulation and in vitro characterization of inhalable rifampicin-loaded PLGA microspheres for sustained lung delivery. Int. J. Pharm. 414, 112-117.

[93] Wang, L.Y., Ma, G.H., Su, Z.G., 2005. Preparation of uniform sized chitosan microspheres by membrane emulsification technique and application as a carrier of protein drug. J. Controlled Release. 106, 62-75.

[94] Nan, F., Wu, J., Qi, F., Liu, Y., Ngai T., Ma, G., 2014. Uniform chitosan-coated alginate particles as emulsifiers for preparation of stable Pickering emulsions with stimulus dependence. Colloids Surf., A. 456, 246-252.

[95] Hoare, T.R., Kohane, D.S., 2008. Hydrogels in drug delivery: Progress and challenges. Polymer. 49, 1993-2007.

[96] Oh, J.K., Drumrighta, R., Siegwart, D.J., Matyjaszewski, K., 2008. The development of microgels/nanogels for drug delivery applications. 33, 448-477.

[97] Hamidi, M., Azadi, A., Rafiei, P., 2008. Hydrogel nanoparticles in drug delivery. Adv. Drug Del. Rev. 60, 1638-1649. 
[98] D’oria, C., Charcosset, C., Barresi, A.A., Fessi, H., 2009. Preparation of solid lipid particles by membrane emulsification-Influence of process parameters. Colloids Surf., A. $338,114-118$.

[99] Vladisavljević, G.T., 2019. Membrane emulsification in pharmaceutics and biotechnology. In Basile, A., Charcosset, C. (eds.), Current Trends and Future Developments on (Bio-) Membranes: Membrane Processes in the Pharmaceutical and Biotechnological Field, Amsterdam: Elsevier, 167-222.

[100] Pan, L., Zhou, J., Ju, F., Zhu, H., 2018. Intranasal delivery of $\alpha$-asarone to the brain with lactoferrin-modified mPEG-PLA nanoparticles prepared by premix membrane emulsification. Drug Delivery Transl. Res. 8, 83-96.

[101] Zhang, W., Wang, L., Liu, Y., Chen, X., Li, J., Yang, T., An, W., Ma, X., Pan, R., Ma, G., 2014. Comparison of PLA microparticles and alum as adjuvants for H5N1 influenza split vaccine: adjuvanticity evaluation and preliminary action mode analysis. Pharm. Res. 31, 1015-1031.

[102] Zhang, W., Wang, L., Liu, Y., Chen, X., Li, Q., Jia, J., Yang, T., Qiu, S., Ma, G., 2014. Immune responses to vaccines involving a combined antigene-nanoparticle mixture and nanoparticle-encapsulated antigen formulation. Biomaterials. 35, 6086-6097.

[103] Qi, F., Wu, J., Hao, D., Yang, T., Ren, Y., Ma, G., Su, Z., 2014. Comparative studies on the influences of primary emulsion preparation on properties of uniform-sized exenatideloaded PLGA microspheres. Pharm. Res. 31, 1566-1574.

[104] Ma, T., Wang, L., Yang, T., Wang, D., Ma, G., Wang, S., 2014. PLGA-lipid liposphere as a promising platform for oral delivery of proteins. Colloids Surf. B. 117, 512-519.

[105] Chang, E.P., Hatton, T.A., 2012. Membrane emulsification and solvent pervaporation processes for the continuous synthesis of functional magnetic and Janus nanobeads. Langmuir. 28, 9748-9758.

[106] Yanagishita, T., Maejima, Y., Nishio, K., Masuda, H., 2014. Monodisperse nanoparticles of metal oxides prepared by membrane emulsification using ordered anodic porous alumina. RSC Adv. 4, 1538-1542. 